\title{
Political and Social Correlates of Covid-19 Mortality
}

\author{
Constantin Manuel Bosancianu \\ WZB Berlin \\ Reichpietschufer 50 \\ 10785 Berlin, Germany \\ manuel.bosancianu@wzb.eu
}

\section{Macartan Humphreys}

Columbia University, WZB Berlin

Reichpietschufer 50,

10785 Berlin, Germany

macartan.humphreys@wzb.eu

Nils Lieber

Boston University

270 Bay State Road,

Boston, MA 02215, USA

lieber@bu.edu

\section{Hanno Hilbig}

Harvard University, WZB Berlin

1737 Cambridge Street,

Cambridge, MA 02138, USA

hhilbig@g.harvard.edu

\section{Sampada KC}

University of British Columbia

Buchanan Building, 1866 Main Mall

Vancouver, BC Canada V6T 1Z1

kcsampada@gmail.com 


\begin{abstract}
What political and social features of states help explain the distribution of reported Covid-19 deaths? We survey existing works on (1) state capacity, (2) political institutions, (3) political priorities, and (4) social structures to identify national-level political and social characteristics that may help explain variation in the ability of societies to limit Covid-19 mortality. Accounting for a simple set of Lassochosen controls, we find that measures of interpersonal and institutional trust are persistently associated with reported Covid-19 deaths in theory-consistent directions. Beyond this, however, patterns are poorly predicted by existing theories, and by arguments in the popular press focused on populist governments, women-led governments, and pandemic preparedness. Expert predictions of mortality patterns associated with state capacity, democracy, and inequality, do no better than chance. Overall, our analysis highlights the challenges our discipline's theories face in accounting for political responses to unanticipated, society-wide crises.
\end{abstract}

Word count: 9,638 


\section{Acknowledgements}

We wish to extend warm thanks for detailed comments and critiques from Chris Blattman, Zoltan Fazekas, James Fearon, Guy Grossman, Stéphane Helleringer, Jonas Hierman, John Huber, Nahomi Ichino, Kimuli Kasara, Friederike Kelle, Evan Lieberman, Ellen Lust, Jim Robinson, Michael Ross, Heike Solga, Federico Vegetti, Shana Warren, Chagai Weiss, Rebecca Weitz-Shapiro, Georg Weizsäcker, Michael Zürn, and participants in the "WZB Talks" seminar series. We thank Vartika Savarna and Sona Jose for research assistance. Special thanks to Miriam Golden for two sets of deep and detailed comments and to Kim Yi Dionne for many valuable discussions, insights, and contributions to this project. 


\section{Introduction}

What features have rendered polities and societies better able to respond to the threat of Covid-19? In the spring of 2020, we reviewed literatures in political science and cognate disciplines that identify political and social characteristics that might plausibly make a difference. In the summer of 2020, we surveyed social scientists, asking them to report their expectations about the relationship between measures of three of these characteristics - state capacity, democracy, and economic inequality - and mortality one year later. In the summer of 2021, we put these predictions to the test, assessing whether conditional correlations aligned with theoretical expectations. Overall, we find mixed evidence for theories about government and societal responses to large-scale crises, and find that mortality patterns have largely moved against the expectations of experts.

In the early days of the pandemic, public discussion focused heavily on country-level political and social explanations for the uneven cross-national impact of Covid-19. The New York Times noted that countries that had recently experienced other epidemics "knew the drill" and were better prepared to respond quickly to the current pandemic. Associated Press cautioned that Africa and Latin America were "fragile targets" because under-resourced health systems made them the "least prepared." Articles in the Washington Post highlighted how countries led by women had responded quickly and effectively, and that these women leaders offered "voices of reason." Political polarization drove "fake news" and misguided government responses, according to the Times of India. "Populism kills," warned Der Spiegel.

How consistent are these popular arguments with social scientific accounts of state-level responses to public health crises? There is not, as yet, a ready answer. With a number of important exceptions - primarily focused on low-income countries (Patterson 2006; Lieberman 2007, 2009; Dionne 2011; Blair, Morse, and Tsai 2017; Chigudu 2020)—political scientists do not typically study disease outcomes. But they do examine how governments behave, and how groups (fail to) overcome problems of collective action, sometimes in the wake of crises with correlated risks, such as economic collapse or natural disasters. If disease outcomes prove to be a function of appropriate government responses, and the willingness of groups in 
diverse societies to comply with government health directives, insights from political economy may help us understand how states fare in the wake of Covid-19.

We organize our discussion around four classes of explanations, focused on (1) state capacity, (2) political institutions, (3) political priorities, and (4) social structures. We then evaluate the extent to which a set of widely-used, national-level measures of each inform cross-sectional patterns in the distribution of the disease burden, accounting for a set of demographic covariates identified via a Lasso procedure.

We describe our primary outcome measure in the next section. Section 3 describes theories of states, governments, and societies that could plausibly explain variation in mortality. Section 4 discusses our findings. Section 5 discusses potential implications and concludes.

\section{Outcome: Reported cumulative deaths per capita}

Using data from the ECDC weekly reports (https://www.ecdc.europa.eu) and population data from the World Bank, we focus on reported (logged) cumulative deaths per capita from Covid-19. Normalizing deaths by population puts countries on a more comparable scale - the outcome can be thought of as the risk to a random individual in a polity. Logging per capita deaths helps address skewing in the data and reflects the substantive idea that responses alter the impact of Covid by orders of magnitude.

Our analysis focuses on reported per capita deaths. We acknowledge concerns about underreporting and the possibility that it may be related to other characteristics of countries relevant for our analysis (see, e.g., Mikkelsen et al. 2015). We attempt to address this concern in two ways. First, we conduct robustness checks for our main results with an arguably more reliable measure of Covid-19 fatalities: excess deaths. Excess mortality captures the difference between the total number of deaths during a particular period, and the average number of total deaths over a set of preceding years. This approach addresses concerns about possible undercounting of deaths attributable to Covid-19, as many may die not as a direct consequence of the virus, but due to hardships created by the pandemic. Our core results 
look broadly similar across the two outcome measures.

The limited availability of excess deaths data means we cannot use it as our primary outcome measure. We therefore adopt a second approach, and attempt to take measurement weaknesses into account in our core analyses. We include in our set of controls in each analysis an index from the Global Health Security Index (GHSI) data, which assesses the early detection and reporting of epidemics of potential international concern. ${ }^{1}$

\section{What insights from political economy?}

We draw on a simple framework to organize thinking about how features of a society and its politics might matter for the ultimate outcome of interest: Covid-19-related mortality (see Figure 1). Although we strive to be comprehensive, we acknowledge we cannot capture all potentially relevant variables. Moreover, these variables may be connected to each other in ways not described here. Furthermore, the model focuses on cross-sectional variation and, therefore, does not represent potentially important feedback processes, such as the effects of infections on policy choices. Nevertheless, it captures a set of major channels through which pre-pandemic social and political variables may be causally related to later measures of reported deaths.

In this framework, political variables enter through three families: (1) state capacity, which matters for what a state can do, (2) political institutions, which shape government incentives, and matter for what a government is willing to do, and (3) political priorities, which matter for which policies are chosen. States have responded to the pandemic by enacting policies that require (sometimes drastic) behavioral changes on the part of their populations. The degree to which people comply likely depends on the nature of the policies enacted, how much people trust their governments, and how much they trust each other, which may be affected by (4) social structures (such as ethnic diversity or economic inequality), and by

\footnotetext{
${ }^{1}$ Why not focus on policy as an outcome? Optimal policies, insofar as they are known, depend on (a) the set of policy options available to governments, (b) the welfare costs of different responses, and (c) the country's disease burden, which itself depends on the effectiveness of its prior policies. These features make it hard to form expectations about the relationship between political variables, policy, and deaths. In short, our theories indicate which countries should be responding more effectively, but are typically not fine-grained enough to speak to specific policies.
} 
Figure 1: Model connecting background variables to reported outcomes.

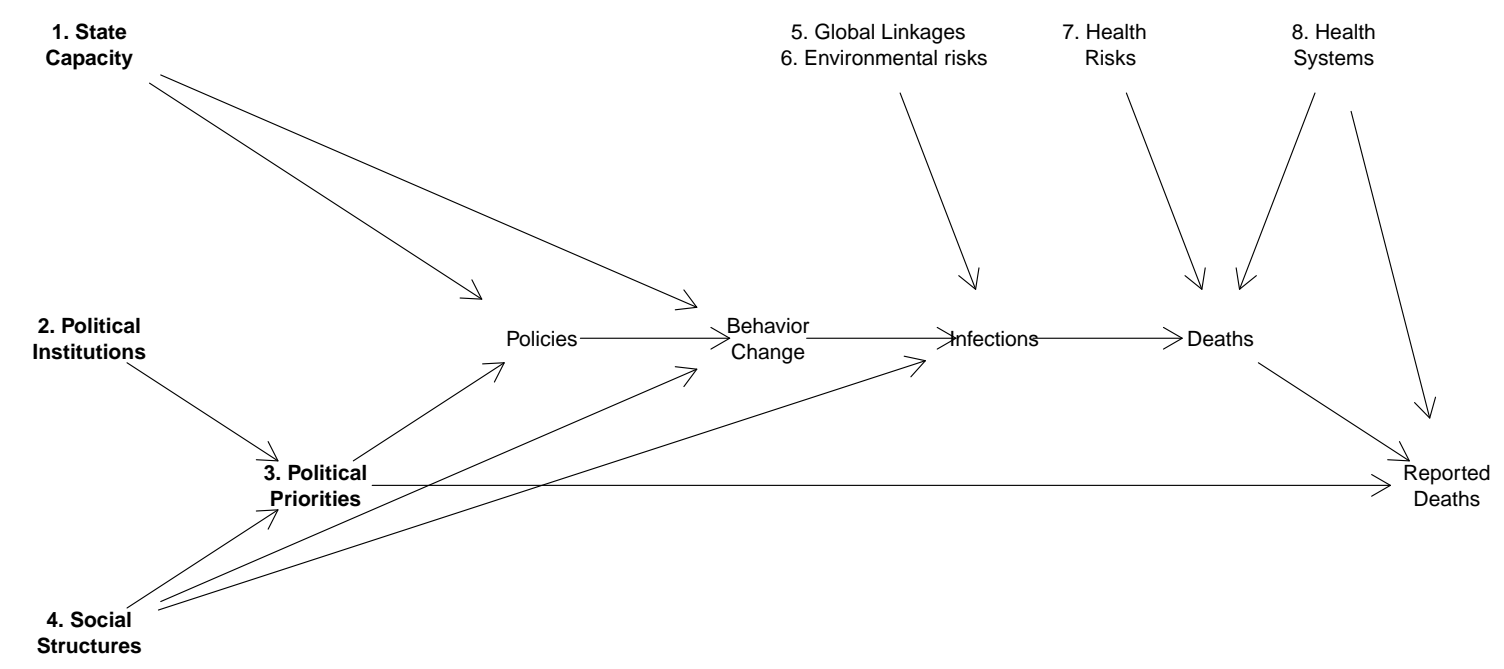

states' enforcement capacities.

Infections are plausibly favored by global physical connectedness, and other features that accelerate virus diffusion, such as urbanization, population density, and according to some evidence, temperature (Wang et al. 2020). These features are grouped here as global linkages and environmental risks. Whether infections lead to deaths depends on underlying health risks (e.g., the prevalence of respiratory disease) in populations and on health system capacities. Last, we observe reported rather than actual deaths. The former may not accurately reflect the latter, given incentives to underreport, or health care capacity constraints, which may lead to undercounting.

We now describe a set of social science explanations that might reasonably link variables in the first four families to Covid-19-related outcomes.

\subsection{State capacity}

Many arguments connect features of state capacity to the ability of governments to react effectively to a public health crisis. Research highlights the multidimensional nature of 
state capacity, including (1) the administrative and coercive capacities of the executive, (2) the expertise and independence of bureaucracies, and (3) the extent of public trust in the government. The literature suggests that improvements in each of these dimensions of state capacity should be associated with fewer Covid-19-related mortalities.

Executive capacity. In a classic description of state weakness, Jackson and Rosberg (1982) describes "national governments [that] exercise only tenuous control over the people, organizations, and activities within their territorial jurisdiction." In extreme cases, wars or widespread political instability undermine the executive's capacity to respond to routine challenges, let alone once-in-a-century-level emergencies. Multiple paths link state fragility and vulnerability to disease mortalities. Conflict devastates institutions and hollows out bureaucracies. It cripples economies, destroys health infrastructure, and induces large population movements (Iqbal and Zorn 2010). It can render populations inaccessible to health and humanitarian workers. It weakens trust in government and, along with it, citizen willingness to comply with government directives. It can weaken intergroup trust and a sense of common fate across communities (ICG 2020).

Bureaucratic capacity. Accounts of bureaucratic capacity emphasize the willingness and ability of bureaucracies to take action in the public interest. In the worst case, bureaucratic corruption can adversely affect service provision (Davis 2004; Fisman and Golden 2017; Gupta, Davoodi, and Tiongson 2001), suggesting weaker responses to a pandemic in settings with high levels of bureaucratic corruption. Even when bureaucracies are working in the public interest, their effectiveness depends on their level of expertise. In the context of Covid-19, bureaucratic learning (Reiter 1995) could arise from prior experience with highly contagious disease outbreaks, such as SARS, Ebola, or MERS (Fox 2020).

Institutional trust. Contagious disease confronts states with the dilemma of ensuring community welfare without infringing on the personal liberties of its individual members. While different regime types may have different inclinations for more or less coercive methods of control, they all require citizens' compliance (Englebert 2002). Trust in government therefore plays a crucial role in states being able to prevent and protect against contagious diseases. Where trust in government is fragile, it will be harder to sustain compliance with 
public health advisories and prevent misinformation, likely leading to greater fatalities.

\subsection{Political institutions}

Government reactions to crises may depend not only on their ability to respond, but also on incentives to do so. We describe below features of political institutions that may shape priorities for the nature, timing, and mix of policy responses. These explanations revolve around (1) the degree of vertical and horizontal coordination that can be achieved in policymaking and implementation when responding to the health crisis, and (2) how institutional features shape accountability and the degree of political responsiveness of the system.

\subsubsection{Centralized decision-making}

Decentralization. A state's capacity to respond to crises may depend on the way decisionmaking authority is dispersed within it. Decentralization can lead to policy experimentation and healthy competition between sub-national units (Weingast 1995), translating into more efficient service provision (Brennan and Buchanan 1980). It should also improve accountability by increasing the capacity of voters to monitor the elected representatives that make subnational decisions (Treisman 2002), and improve crisis reaction times. Decentralization has been found to improve local health service provision by improving accountability and resilience in health centers (Kumar and Prakash 2017). However, decentralization may also make monitoring harder for central authorities, and produce principal-agent coordination failures (Wibbels 2005). Efficiency losses might also result from capture of authorities by strong local vested interests (Neyapti 2010), or from susceptibility to waste and manifest themselves in higher corruption and worse health outcomes.

Veto players. A large literature identifies effects of multiple "veto points" - that is, systems in which the consent of multiple actors is required to change policies (Tsebelis 2002). The presence of many veto points can help ensure policy stability and ensure broad support; conversely, veto points lock in the status quo and prevent agile political responses (Ha and Kang 2015), though this itself may result in greater bureaucratic autonomy. It is also possible veto players have a diminished role in this context; crises give an executive opportunities 
to take charge, reducing the importance of finer institutional arrangements. This set of competing arguments suggests that centralized decision-making could either help or hinder states' responses to the Covid-19 pandemic (Oltermann 2020; Feldman 2020).

\subsubsection{Political responsiveness}

Democratic institutions. Most famously, Amartya Sen (1982) has argued that famines do not happen in democracies. Others have built on this logic of higher accountability and political responsiveness to show political accountability is associated with greater spending on public goods (Boix 2001; Ghobarah, Huth, and Russett 2004), and particularly on the health system (Besley and Kudamatsu 2006). Democracies have also been shown to be more successful at reducing disease burdens and infant mortality (Bollyky et al. 2019; Lake and Baum 2001; Diaz-Cayeros, Estévez, and Magaloni 2016). ${ }^{2}$

Proportional representation (PR). In democracies, the rules structuring electoral competition affect policy outcomes and public goods distribution by shaping how political parties compete and coalesce (Iversen and Soskice 2006). These can set the parameters for executive action and interest group influence (Immergut 1992). In multiple accounts, majoritarian systems incentivize politicians to target goods to narrow constituencies and, compared to PR systems, have lower provision of universal public goods (Persson and Tabellini 2000) and less redistribution. Selway (2015) shows how the inclusive coalitions found in PR systems lead to greater distribution of health facilities and resources, resulting in better health outcomes.

Media independence. Besley and Burgess (2002) extend Sen's logic and focus on the role of the media, an institution that acts in a similar way to democratic constraints, by keeping politicians attuned to popular preferences. In their account, the media is important for incentivizing governments: if governments get credit from media outlets for responding to crises, they have greater incentives to do so. The media can also take a more confrontational stance, and see its role as "speaking truth to power." This can provide incentives to politicians to capture the media sector (Besley and Prat 2006), resulting in poorer government

\footnotetext{
${ }^{2}$ For a contrary view see M. Ross (2006), who argues that while democracies spend more on health, this does not benefit populations widely.
} 
performance (Snyder Jr. and Strömberg 2010).

Natural resource dependency. Heavy dependence on natural resources weakens the accountability link that an independent media and other democratic institutions promote. Karl (1997), documenting the "paradox of plenty," highlights ways in which the availability of rents from natural resources can weaken state-society linkages (see also M. L. Ross 2015), as citizens monitor governments less closely when they are funded by windfalls rather than taxes (Paler 2013).

\subsection{Political priorities}

Governments have faced many choices in how to respond to the pandemic, each balancing competing considerations: expected health outcomes, economic disruption, expected compliance, civil rights, or implementation capacity, among others. These choices may be affected by (1) characteristics of the governments themselves and of their political environment, and (2) features of the constituencies whose interests the governing party or coalition serves.

Electoral pressures. Political action is often most intense when electoral pressures are high - when seats are contested, or in the run-up to elections. Nordhaus (1975) provides a classic account of "political business cycles," focusing on ways in which economic policies respond to electoral incentives. A plausible account starts with the sensitivity of the electorate to economic downturns, and particularly unemployment (Dassonneville and Lewis-Beck 2013). A standard response to the pandemic has been to impose lockdown measures of varying intensity, which have resulted, in the short term, in job losses and economic contraction (Strauss 2020). Politicians up for reelection in the near future should be more sensitive to the economic damage caused by strict lockdown measures, and may correspondingly opt for less strict guidelines at the risk of higher mortality rates. On the other hand, voters may place more weight on health outcomes, and governments may escape punishment for economic downturns if they can claim that Covid-19 was an unpredictable event (D'Elia and Norpoth 2014).

Populism. In Kyle and Meyer (2020)'s definition, populist political leaders are united 
by two claims: "(1) that a country's 'true people' are locked into a moral conflict with 'outsiders' and (2) that nothing should constrain the will of the 'true people." In this account, populist politicians exacerbate cultural divisions, take a skeptical position towards science and expertise, and can be erratic in their decision-making. Insofar as populist leaders are motivated by electoral considerations to take anti-establishment positions, they can also weaken public services, such as healthcare provision. Recent cross-national studies offer evidence that populist leaders contribute to a deterioration of both government accountability and state capacity (Rode and Revuelta 2015), suggesting multiple paths through which populist politics could result in less effective government responses to the Covid-19 crisis.

The ideological orientation of the government may also shape its response to a public health crisis. Two arguments suggest that governments led by right-wing parties may be less successful in combating Covid-19. First, reflecting priorities put on economic costs versus social welfare, more right-leaning parties may implement policies that place more weight on protecting property (Hicks and Swank 1992; McDonald, Mendes, and Kim 2007). Second, many policies employed to combat the coronavirus involve nontrivial infringements upon civil liberties - such as freedom of movement - for public benefits (Gostin and Hodge 2020; Wynia 2007), which may be anathema for right-leaning parties.

Women leaders. Multiple studies suggest that a leader's gender matters for shaping policy outcomes (Chattopadhyay and Duflo 2004; Iyer et al. 2012). In particular, evidence points to a gender effect in preferences for public goods, with women leaders favouring more expenditures on public health (Clayton and Zetterberg 2018). Studies have also shown improvement in health outcomes, particularly child health outcomes, as a consequence of increased representation of women in policy positions (Bhalotra and Clots-Figueras 2014). Prior research therefore leads us to expect women leaders to prioritize public health spending, making it plausible that female leadership could lead to fewer Covid-19 related deaths.

\subsection{Social structures}

Research in political economy has focused on whether and how social divisions may translate into welfare outcomes. Here we describe arguments for the conditioning effects of (1) ethnic 
diversity, (2) economic inequality, and (3) low levels of interpersonal trust on the types of coordinated actions required during public health crises.

Ethnic diversity. An extensive literature documents obstacles posed by ethnic diversity for collective action, coordination, informal sanctioning of antisocial behavior, intergroup empathy, and trust, arguably all of which should weaken government effectiveness and public compliance in the face of a public health crisis (Alesina and Ferrara 2005; Habyarimana et al. 2007; Baldwin and Huber 2010). Lieberman (2009) argues that deep social divisions lead to poorly devised public policies in the face of a health crisis, as popular understandings of epidemics can take on an ethnic dimension, resulting in scapegoating and false beliefs about risks and immunities associated with different groups. Taken together, these studies suggest that more diverse societies should be less able (or willing) to contain a pandemic.

On the other hand, social fragmentation might actually slow the spread of disease. Betweengroup interactions are typically less frequent than within-group interactions, with consequences for the spread of information and the ability to sanction antisocial behavior within ethnic networks (Fearon and Laitin 1996; Larson 2017). Given fewer interactions across groups, it is reasonable to expect that the spread of the disease should be more limited within ethnically diverse societies, and we should expect fewer Covid-19 deaths.

Economic inequality. Income inequality might increase Covid-19 mortality through two channels. First, an absolute income effect: a mean-preserving increase in inequality implies that incomes have decreased for a sub-group, making medical treatment more expensive (Leigh, Jencks, and Smeeding 2009), particularly in systems with private healthcare markets. As comorbidities have been associated with an increased mortality rate attributed to Covid-19 (Zhou et al. 2020), negative income shocks would lead to a higher mortality rate in more unequal countries.

The second points to the society-wide effects of inequality, which may affect the efficiency with which a country can respond to the challenge posed by the pandemic. By decreasing aggregate levels of trust (Elgar 2010), income inequality can impede the provision of public goods, including a well-funded and efficient health system (Ghobarah, Huth, and Russett 
2004). Lack of access to such a system can heighten the prevalence of comorbidities in the population, which would worsen the mortality rate of the Covid-19 virus. By eroding social cohesion (Barnett and Whiteside 2002), inequality can also undermine the kind of societal coordination needed to combat a pandemic.

Interpersonal trust. In addition to serving as an underlying mechanism, widespread societal norms of mistrust toward others (Nunn and Wantchekon 2011) may also exert an independent effect. Lower levels of interpersonal trust can exacerbate collective action problems (Gächter, Herrmann, and Thöni 2004; Parks, Henager, and Scamahorn 1996). Responding to a pandemic requires cooperation on a large scale - from agreeing to follow health guidelines that involve changes in routine behavior, to compliance with social distancing rules, to potentially costly lockdown directives. People might reasonably be more willing to take individually costly actions that help avoid disease spread if they believe other members of their society would do the same. If communities themselves are involved in ensuring the health of their members, low levels of interpersonal trust in the community could hinder cooperation.

\section{Empirical strategy}

Our primary goal is to assess whether associations are in line with explanations identified in the previous sections. Although causal accounts motivate the set of covariates we focus on, we do not estimate causal effects. We are mindful of concerns about confounding, self-selection, spillover dynamics, post-treatment bias, and the challenges of inferring micro-level causal relations from a macro-level analysis. We note, moreover, that even well-identified estimates of causal effects, though desirable, are not themselves sufficient to explain disease distributions. ${ }^{3}$

We report both conditional and unconditional correlations between political and social characteristics and per capita mortalities from the moment countries began recording deaths. Conditional correlations focus on variation explained by social and political factors beyond what is accounted for by demographic and health controls. To identify the most relevant

\footnotetext{
${ }^{3}$ For instance, Carleton et al. (2020) provide valuable causal evidence linking exogenous changes in temperature to virus transmission, yet whether hotter places experience greater transmission depends on other ways that these places are different, including adaptations to varying temperatures in different periods.
} 
controls, we use a Lasso ("least absolute shrinkage and selection operator") approach, applied to March 15, 2020 data. The variables selected are healthcare quality index (GHSI), healthcare spending/capita, life expectancy, and respiratory disease prevalence (see Section 4 on page 3 of the Appendix for more details). These control variables are always included when we report conditional correlations between social and political factors and per-capita Covid-19 deaths. To these controls we add an index of the quality of early detection and reporting of epidemics from the GHSI. Control variables account for around two fifths of the cross-national variation in per-capita mortality (see Figure 2).

Figure 2: Share of variation explained by controls

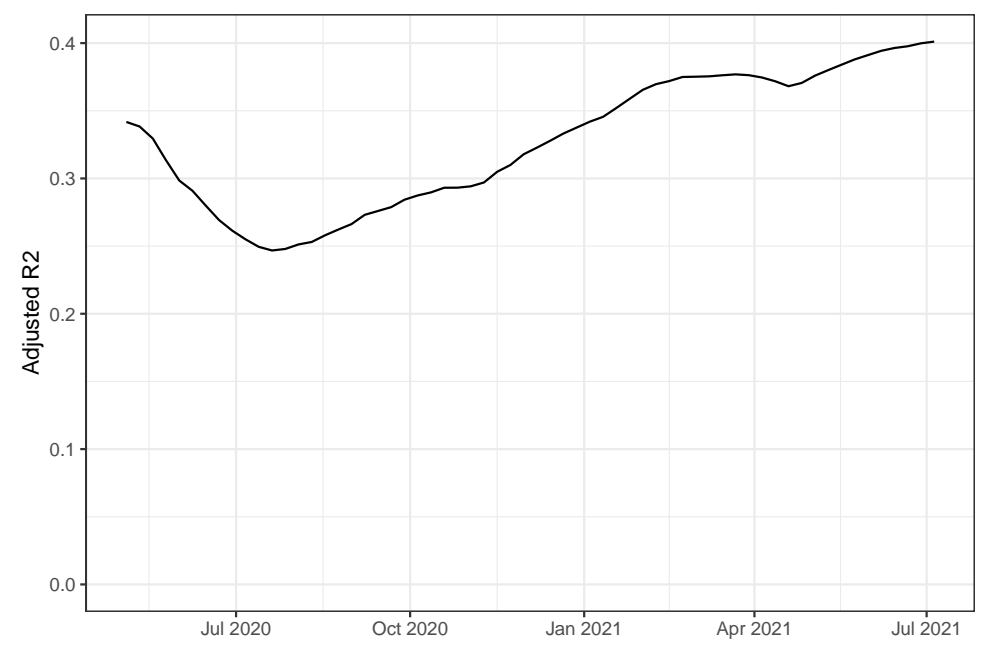

All measures used and their sources are summarized in Table 1 on page 1 of the Appendix. Although we include measures for many of the major concepts discussed above, for some we have to contend with limited sample availability - notably trust in government and interpersonal trust. ${ }^{4}$ Further details of these measures are provided in Table 2 on page 2 of the Appendix. For these analyses, we calculate robust standard errors and $p$-values using the Benjamini-Hochberg procedure to take account of multiple comparisons.

Outcome measurement. To avoid missingness for cases with zero deaths, we take the log of one plus the number of reported deaths divided by total population. We estimate associations with cumulative death counts at four points in time: June and October 2020, February and

\footnotetext{
${ }^{4}$ Trust in government is compiled from waves 1-7 of the World Values Survey, and the 2018 round of the Latin Barometer. Differences in question format made enlarging the sample past 83 countries impossible.
} 
June 2021. In all cases we take the first available weekly report from that month, except for June 2021, where we use the last available date: June 28th.

Predictors. Predictors are typically measured for 2018 or 2019, with few exceptions. For both interpersonal and institutional trust we selected the most recent survey year available for a country, but allowed surveys fielded as far back as 2009, assuming that trust is a stable trait in the medium term. For the Gini index, information for 2018 is only available for a subset of (wealthy) countries. To expand the sample, we average Gini for all valid observations in the 2010-2018 period. Oil rents information was available only for 2017. Ethnic fractionalization is computed using information from around 2000.

Analysis. The coefficients are from linear models using z-standardized predictors. The estimates can therefore be interpreted as differences in logged units of mortality per capita associated with a standard deviation shift in the variable of interest. We show confidence intervals using robust standard errors. ${ }^{5}$ Stars placed above a point estimate on the coefficient plots indicate that its $p$ value is smaller than 0.05 after the adjustment for multiple comparisons. The analysis is implemented on a global sample. In Section 7 of the Appendix (Figure 2 on page 9), we limit analyses to the two thirds of countries with per capita income below USD 20,000 and see the same broad patterns persisting.

In Figure 3 we show the variation in outcomes that can be explained by these predictors when selected using a Lasso procedure. The left panel shows the contemporaneous success of a Lasso model in explaining variation - that is, the share of time $t$ variation explained by Lasso sampled predictors in time $t$. We note two patterns: first, the scope for explanation increases markedly over time, and second, adding political and social variables greatly increases predictive power - with improvements on the order of $30 \%$. The right panel shows the predictive performance: the share of variation in July 2021 mortality explained by predictors selected in time $t$. We see from this graph that predictors generally performed better when predicting future rather than contemporaneous behavior, possibly reflecting a settling of patterns. We see again here that including political and social covariates improves performance. This analysis gives some confidence that there are systematic features to

\footnotetext{
${ }^{5}$ Coefficients and standard errors are calculated using lm_robust () from the estimatr package for R.
} 
variation in mortality that can be explained by standard social and political variables.

Figure 3: Share of variation explainable by political and non-political variables

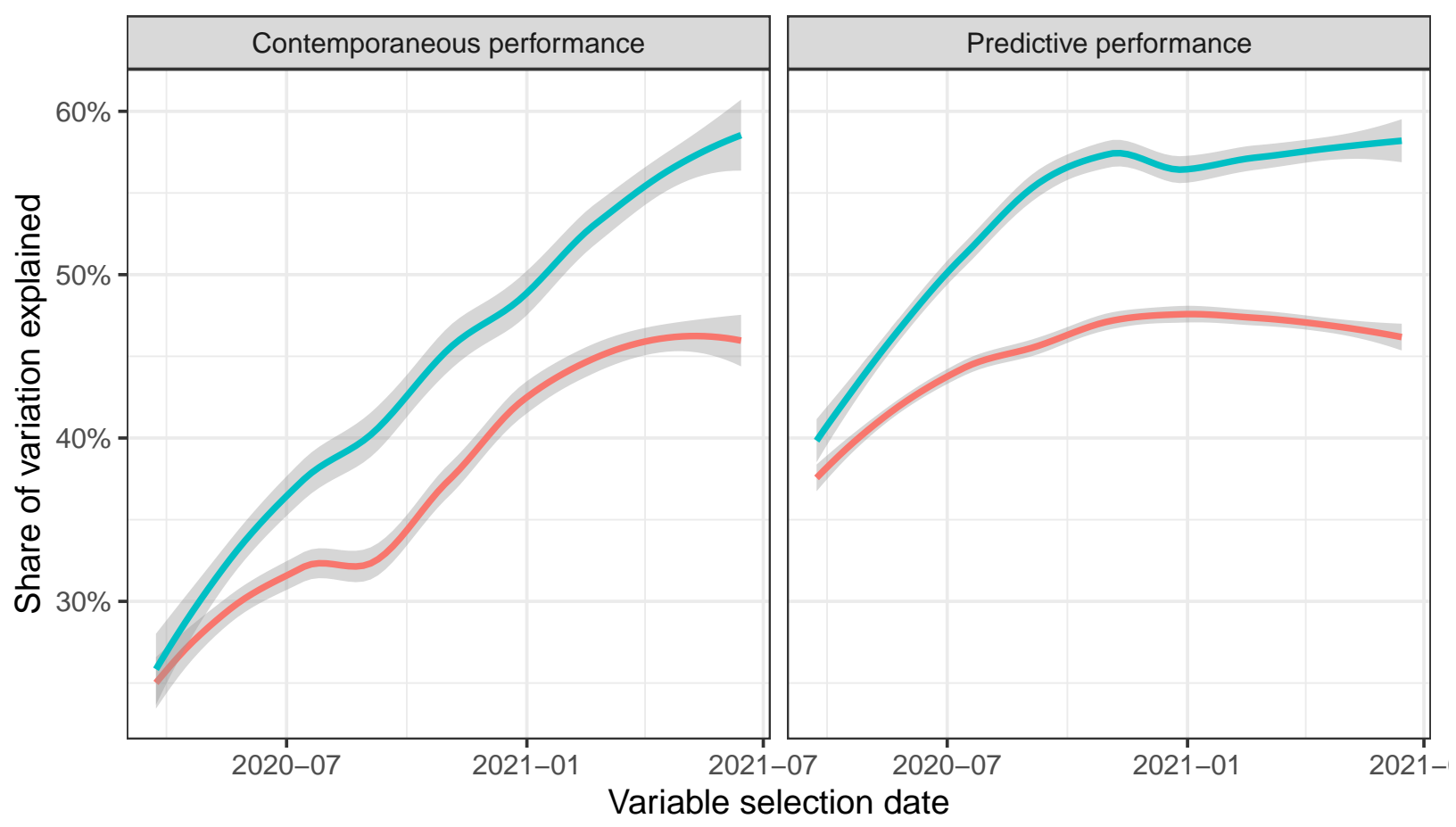

Base _- Exclude political vars — Include political vars Shaded bands reflect variation in performance across repeated implementation of Lasso procedures.

We augment our primary analysis with data from a survey of more than a hundred social scientists, fielded in July and August 2020, that gathered expectations about the relationship between (then) future Covid-19 deaths in June 2021 and measures of democracy, economic inequality, and state fragility. We asked separately for beliefs about underlying causal relationships and correlations, asking respondents to put weights on whether they expected the relationship between these three variables and mortality would be positive, negative, or null in June 2021. We elicited expectations about observed future correlations given three different causal scenarios (a positive effect, negative effect, or no effect).

Answers to these questions allow us to assess three quantities of interest. First, which of these three variables do experts believe have a clear directional causal effect on Covid-19 deaths? Second, what are respondents' raw predictions over the patterns they expect to observe? 
Third, and most importantly, how should we update over causal hypotheses given observed correlations? Respondents might believe, for instance, that confounding is so great that the observed correlations will be entirely uninformative about underlying causal relationships. We use findings from this survey below to both interpret findings and assess how we should update on causal theories given correlations in the data.

\subsection{Results}

Figure 4 shows the full set of conditional and unconditional associations between political and social characteristics and logged per capita Covid-19 deaths. ${ }^{6}$

We focus first on the most recent set of results, from June 2021, and from specifications that include Lasso-derived controls. Bivariate associations are also reported for convenience, but are not interpreted. A broad overview of this fourth column of panels shows that no family of explanations receives unequivocal support and, within some families, we observe seemingly contradictory results.

Arguments about state capacity receive mixed support at best. Indicators of government effectiveness, public sector corruption, and pandemic preparedness are uncorrelated with Covid-19 mortalities in the present period, while a standard measure of state fragility has a negative association - more fragile states experience fewer deaths - against expectations. Two measures of state capacity do follow theoretical expectations. First, prior pandemic exposure is associated with fewer deaths, as theories of bureaucratic learning would predict. Second, we find a large, significant, negative relationship between institutional trust and mortalities throughout the pandemic. Governments that enjoy the trust of their citizens have consistently experienced fewer deaths.

For political institutions, we find no evidence that standard measures of political centralization, media independence (except the results from February 2021), or natural resource dependence affect cross-national patterns in Covid-19 deaths. We do find significant relationships between mortalities and two key measures of political responsiveness - an aggregate index of liberal

\footnotetext{
${ }^{6}$ Full results are given in Tables 5-8 in Section 6 of the Appendix (pp. 5-8). Table 4 (p. 5) in Section 5 reports the set of predictors that remain significant after accounting for multiple comparisons.
} 
Figure 4: Correlates of Covid-19 outcomes

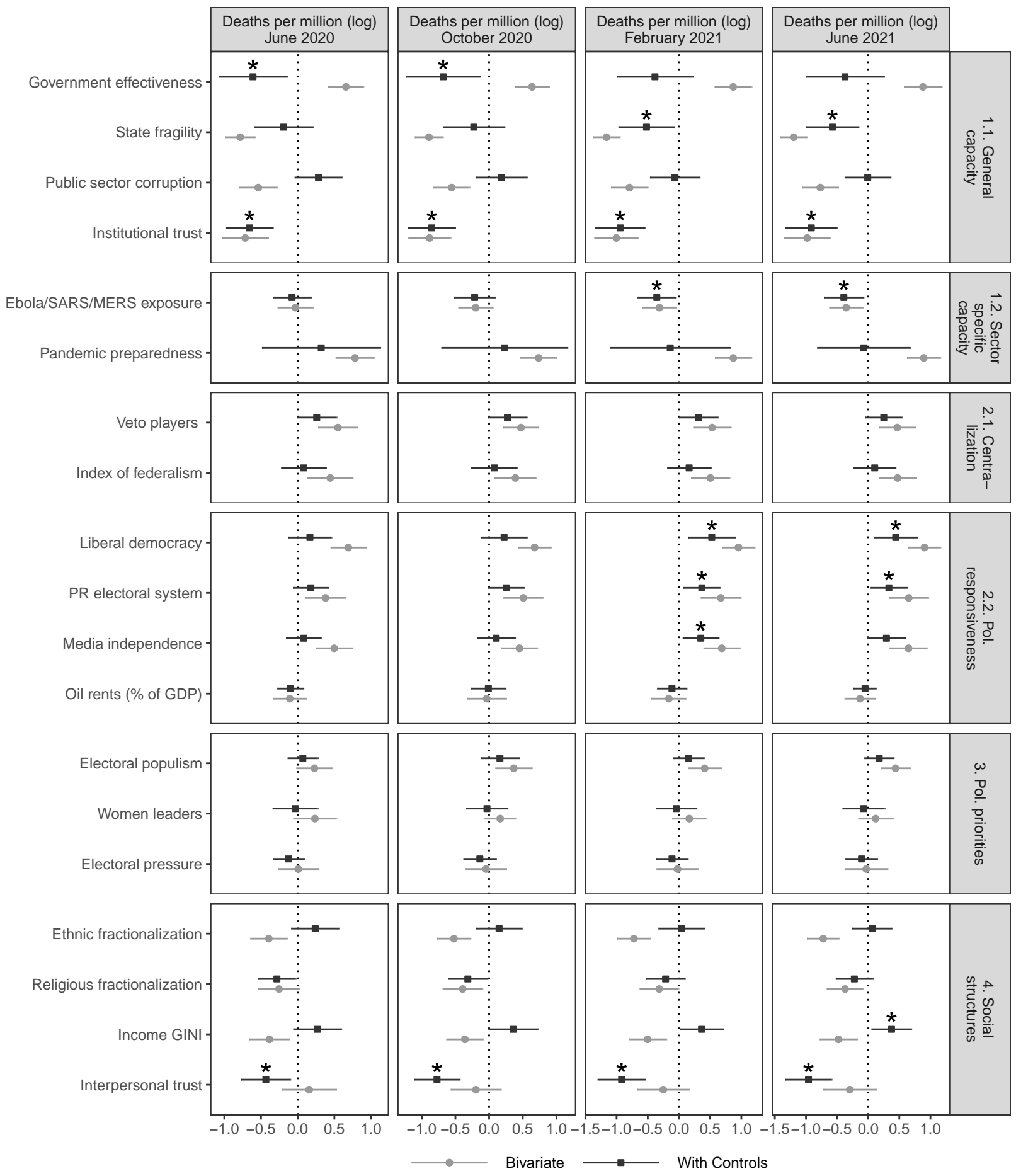

Points represent normalized coefficients from either a bivariate model (circles) or a model with controls (squares). 
democracy and our dummy indicator for a PR electoral system. In both cases, however, the associations are positive - democracies and PR systems experience more deaths - against theoretical expectations.

We find no relationship between measures intended to capture states' political prioritieselectoral populism, electoral pressures, or women leaders-and Covid-19 deaths. This is striking, given the attention that these variables have received in popular discourse.

We find mixed results for explanations focusing on social structures, with no evidence that standard measures of ethnic and religious diversity matter for Covid-19 deaths, but significant relationships in expected directions for measures of economic inequality and interpersonal trust. In the current period (but not earlier ones), higher inequality is indeed associated with worse mortality, and its effect is carried out not only through the interpersonal trust pathway we posit (as shown by our investigations in Table 9 on page 10 of the Appendix). Finally, we find a large and statistically significant negative relationship between interpersonal trust and mortalities that remains robust across time.

In sum, two key patterns emerge from the analysis. The first is the general lack of association between many social and political factors theoretically linked with states' abilities to respond effectively to crises and highlighted in the popular press. We see this clearly when looking at family-specific explanatory sets. The second is the robust negative relationship between two types of trust - institutional and interpersonal - and Covid-19 mortalities. These effects are consistent over time, and work in the direction predicted by studies of trust and collective action. $^{7}$ In both cases the estimated associations are considerably stronger than those of other indicators, at approximately 1 log units change in mortality per capita, though they are also obtained from smaller samples.

Our data suggest that societies with higher levels of interpersonal and institutional trust have fared better in this pandemic. Although we cannot directly test competing mechanisms linking institutional and interpersonal trust and lower mortality, additional analyses, reported in Table 9 of the Appendix, suggest that the two types of trust are independent, rather than

\footnotetext{
${ }^{7}$ See Bargain and Aminjonov (2020), Elgar, Stefaniak, and Wohl (2020) and Oksanen et al. (2020) for similar results for institutional trust early in the pandemic.
} 
tapping into the same source of variation. Including both in the same specification does not substantively impact the magnitude, direction and statistical significance of the estimates.

\subsection{Patterns over time}

Figure 4 shows the generally striking degree of stability in our estimates. Across many variables, we see stability when focusing on conditional associations. In some cases, such as interpersonal trust and exposure to past health crises, the association persists and strengthens with time. Other instances are more fleeting. For economic inequality, we detect an association in June 2021 for the first time, though the estimate maintains its magnitude over time. The positive associations we detect in 2021 for the two political responsiveness factors discussed above fail to show up in 2020. The same happens with prior pandemic exposure, and state fragility. The converse dynamic occurs for government effectiveness. Although government effectiveness may have been important for implementing lockdowns and other restrictions in the pandemic's early stages, as the pandemic spread and even well-performing countries loosened up restrictions, mortality figures caught up. By 2021, more and less effective governments had comparable mortality levels.

\subsection{Implied expert learning}

In the summer of 2020, social scientists who completed our experts survey expected income

inequality and state fragility to increase Covid-19 mortality but did not have clear expectations about liberal democracy. In addition, most respondents' reported beliefs about underlying causal relationships aligned with those about the correlations they expected to observe in June 2021. This suggests that researchers think observed correlations provide a good signal of underlying causal relationships, and are not greatly concerned about measurement error or confounding in these cross-national relationships. Figure 6 on page 16 of the Appendix shows in more detail the distribution of elicited beliefs. These results provide some confidence in the scope for learning about theories from observed correlations.

In Figure 5 we show the implied learning for the three measures from our experts survey (democracy, state fragility, and economic inequality) for the June 2021 data patterns in 
Figure 4. The heavy line shows the average updating we expect. Note that movements reflect changes in (i) expectations from a prior about causal relationships to a posterior given data patterns (x-axis), and (ii) changes in certainty (y-axis). As such, a southeasterly movement means that seeing the correlations we see, a respondent should both increase their expectation of a positive relationship and increase their confidence in their belief. Broadly we see that expectations regarding the role of inequality are strengthened, but beliefs about state fragility and democracy are challenged. We discuss the implications of these patterns in detail in the next section.

Figure 5: Changes from priors to posteriors.
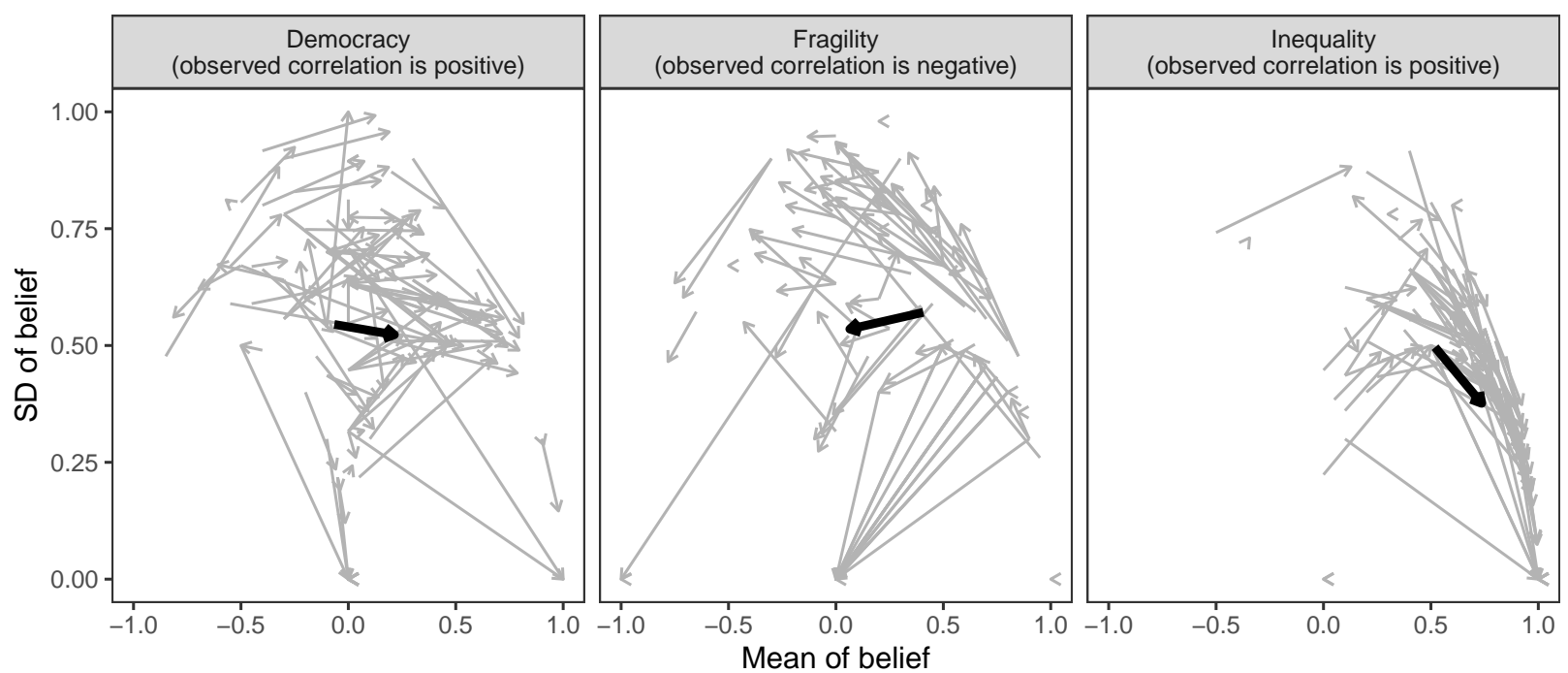

Notes: Each arrow represents prior and posterior beliefs about causal relationships for a given researcher, where the arrow begins at prior beliefs and ends at posterior beliefs. Negative values indicate that a researcher believes a variable has a negative causal effect on Covid-19 mortality, while positive values indicate that researchers believe a given variable has a positive causal effect on Covid-19 mortality. Each panel represents beliefs for one explanatory variable. The figure then shows how researchers should update their beliefs given the observed association between a given variable and Covid-19 mortality. Bold arrows represent the average change between prior and posterior beliefs given the observed associations. The length of the arrows can be interpreted as the degree to which researchers should update their beliefs according to the evidence - for very long arrows, researchers update strongly, while short arrows indicate that the observed evidence has little effect on beliefs about the underlying causal relationship.

For economic inequality, on the other hand, evidence of a positive correlation should increase expectations, and the certainty that the underlying causal relationship is also positive. For democracy, although, on average, respondents believe that it does not have an important 
effect, upon seeing evidence of a positive correlation they are expected to update to a posterior that is in the direction of the observed data pattern, with no change in certainty.

Overall, these survey results show what the learning, in terms of inferences about causal relationships, should be given the distribution of priors. Another takeaway is that researchers think data patterns are informative about underlying causal relationships and are expected to change their beliefs when patterns change. Therefore, although there are many reasons for why the correlations cannot be interpreted as estimates of causal effects (due to potential concerns about confounding, selection, and complex interactions), the Bayesian results point to the value of correlations in informing beliefs about qualitative causal relationships.

\subsection{Robustness}

We next assess whether our core findings are driven by error in our measure of Covid-19 fatalities. We replicate Figure 4 using a measure of excess deaths over the same period relative to pre-pandemic years. We note that the correlation between excess and reported Covid-19 deaths, among countries for which data on both exists, is fairly strong: 66\%. As shown in the Appendix, Figure 7 on page 17, we also find that patterns using excess deaths are similar to our main results - in those cases where we have data on both measures - and our two measures of trust remain strongly correlated with both measures of deaths.

\section{Discussion}

\subsection{Theoretical implications}

What implications can we draw from our results? We focus our discussion on the possibility that existing theories may not be well-suited to help us understand coordinated political action in the wake of the kind of novel, society-wide threats posed by Covid-19.

State capacity. We saw conflicting results on state capacity-with a negative correlation between state fragility and mortality, and no discernible association for measures of effectiveness and preparedness. Recall that this negative relation is conditional on the best measures we have of data quality. One possible explanation for this is that existing theories of state 
capacity simply do not capture features necessary to address new threats. Classic accounts of state effectiveness typically assume that governments can know what policies are optimal. Without such knowledge, the importance of the state's ability to act is unclear. A second possibility is that the characteristics we associate with state strength may, in fact, have adverse effects. We often think of capacity as a state's ability to "reach" its citizens (to tax, count them in a census, or provide public goods). In the Covid-19 pandemic, however, a state's weakness along this dimension may initially be beneficial. If more fragile countries are cut off from external and internal sources of contagion, this may in fact slow the spread of disease.

Our experts survey provides new perspectives on these mixed findings. Initial expectations (ICG 2020) favored a strong positive relationship between state failure and mortality, as did participants in our experts survey. Our primary results call these expectations into question. Bayesian updating should lead researchers to revise their expectations regarding its relationship with future mortality, on average, to closer to zero, while also increasing their uncertainty.

Though our data does not allow us to directly test mechanisms linking institutional trust to pandemic mortality, existing work points to the importance of such trust for citizen compliance with government directives. Societies with higher levels of trust in political actors and institutions exhibit greater compliance with Covid-19 mobility restrictions (Bargain and Aminjonov 2020) and other measures (Han et al. 2021). These compliant behaviors reduce virus transmission and cut mortality by alleviating the pressures on health care systems.

Political institutions. We also see unexpected patterns for centralization and political responsiveness, especially in the second wave of the pandemic. More democratic contexts, with PR electoral systems and a more independent media, experienced a higher mortality rate. Our results go against those obtained by Karabulut et al. (2021) for data collected in late 2020, as well as those of Cepaluni, Dorsch, and Branyiczki (2020) for the initial stages of the pandemic, in that we find no clear effect of democracy on mortality. They also go against established literatures connecting democracy to the aversion of disasters (Sen 1982). Part of the effect we uncover is undoubtedly due to the specific patterns of geographic spread of the 
pandemic over time. The rest of the story may hold deeper implications for how we judge the role of political responsiveness in the face of a global health emergency on the scale of Covid-19.

Differential political responsiveness often manifests itself in instances where sub-groups in the citizenry have conflicting priorities, or when a specific social or economic group has an undue influence on political processes. The differential behavior of democracies, and of specific democratic institutions, may be less marked in settings where distributive considerations are less salient, as may be the case with a disease that has global impacts. Our experts survey results suggest that researchers were indeed ambivalent about the importance of democracy for addressing the pandemic but our findings suggest that in most cases - and on average - they should revise their beliefs to a more negative position.

Political priorities. Journalistic (Chamorro-Premuzic and Wittenberg-Cox 2020), and early academic accounts (Coscieme et al. 2020; Garikipati and Kambhampati 2021) emphasized the superior performance of women political leaders during the pandemic in terms of reduced fatalities. In contrast, focusing only on women holding the highest national executive political office, and looking at outcomes over a full year of the pandemic, we find no evidence that women leaders are linked to a better performance at any point during the Covid-19 crisis (see also Piscopo 2020).

Popular and academic attention has focused on the potential impact of populism on pandemic outcomes (Gugushvili et al. 2020; Mounk 2021; Sánchez-Talanquer et al. 2021). Our results again point to the possibility of no relationship. We show that this bivariate association disappears once controls are added. However, it's worth pointing out that our results only hold for our measure of electoral populists, i.e. leaders who ran an election campaign with populist overtones. Other indicators, targeting the societal dimensions of populism, might show a link to mortality, though we are unable to explore this here.

As in the other families, theories that focus on variation in priorities were developed in situations where there is substantial disagreement on political priorities. Although Covid-19 responses have certainly been politicized in some countries, they have played a surprisingly 
minor role in many electoral settings, perhaps because health issues are not seen as political issues (Acharya, Gerring, and Reeves 2020), or because there is broad policy agreement between different political actors. In the 2021 German election, for instance, none of the 38 issues used to differentiate parties in the popular "Wahl-O-Mat" voting advice application covered domestic Covid-19 responses.

Social structures. A key insight to emerge from our results is the robust positive relationship between interpersonal trust and pandemic mortality - an association that only increases in strength over time. As with institutional trust, it is reasonable to expect interpersonal trust to increase other-regarding behaviors, although the connection is not as straightforward as for political trust (Min 2020). Large-scale coordination in the face of a public emergency is expected to be easier in countries with higher levels of trust, though such a climate also

fosters tighter community networks and more frequent interactions, which could ultimately result in more infections and deaths. Conversely, in low trust contexts suspicion might have positive externalities - when trusting others less we become more cautious, which could serve to reduce the infection rate. Our results provide some support for the coordination and increased caution arguments.

\subsection{Broader implications}

What do these findings mean for the ability of social science theories to help us understand country-level patterns of variation in Covid-19 mortalities? The two features that are consistently related to mortality, conditional on healthcare system quality and population health, are trust in the government and trust in other people. But many of the political features highlighted in our discipline's theories do not seem to matter for states' ability to reduce mortality during the pandemic. Further, expert predictions about which of three important variables would matter turned out to be correct in only one out of three cases and wrong in two of three cases. In other words, no better than chance.

As suggested above, one reason for these unexpected (non)findings may simply be that the universal nature of the challenges posed by Covid-19 renders some of our discipline's theories about political institutions and political priorities — which often assume clear distributional 
stakes - less relevant. Politics in the wake of Covid-19 may simply be too different from "politics as usual" for our theories to give us much leverage. In contrast, trust — whether in government or in each other - plausibly should matter for society-wide challenges, and indeed we find that it does.

More broadly, our (largely null or counter-to-expectation) results may be a reflection of the way that we organize and structure our research. Many of our theories are based on analyses that predict events that have already taken place, and are selected because they explain the past, not the future. It is hard to be conscious of scope conditions when the theories are developed and tested in times where the scope conditions hold. Approaches that seek to select on the basis of out-of-sample prediction generally focus on predicting the same outcomes in different sites and not different outcomes that should be explained by the same overarching theories. A reorientation of research towards the development of mid-level theories intended specifically to explain broad classes of events may leave us in a better position to explain future variation and not only past variation. 


\section{References}

Acharya, Arnab, John Gerring, and Aaron Reeves. 2020. "Is Health Politically Irrelevant? Experimental Evidence During a Global Pandemic." BMJ Global Health 5 (10): e004222. Alesina, Alberto, and Eliana La Ferrara. 2005. "Ethnic Diversity and Economic Performance." Journal of Economic Literature 43 (3): 762-800.

Baldwin, Kate, and John D. Huber. 2010. "Economic Versus Cultural Differences: Forms of Ethnic Diversity and Public Goods Provision." American Political Science Review 104 (4): $644-62$.

Bargain, Olivier, and Ulugbek Aminjonov. 2020. "Trust and compliance to public health policies in times of COVID-19." Journal of Public Economics 192: 104316. https: //doi.org/10.1016/j.jpubeco.2020.104316.

Barnett, Tony, and Alan Whiteside. 2002. AIDS in the Twenty-First Century: Disease and Globalization. Basingstoke: Palgrave Macmillan.

Besley, Timothy, and Robin Burgess. 2002. "The Political Economy of Government Responsiveness: Theory and Evidence from India." The Quarterly Journal of Economics 117 (4): $1415-51$.

Besley, Timothy, and Masayuki Kudamatsu. 2006. "Health and democracy." The American Economic Review 96 (2): 313-18.

Besley, Timothy, and Andrea Prat. 2006. "Handcuffs for the Grabbing Hand? Media Capture and Government Accountability." American Economic Review 96 (3): 720-36.

Bhalotra, Sonia, and Irma Clots-Figueras. 2014. "Health and the Political Agency of Women." American Economic Journal: Economic Policy 6 (2): 164-97.

Blair, Robert A., Benjamin S. Morse, and Lily L. Tsai. 2017. "Public Health and Public Trust: Survey Evidence from the Ebola Virus Disease Epidemic in Liberia." Social Science Es Medicine 172: 89-97.

Boix, Carles. 2001. "Democracy, Development, and the Public Sector." American Journal of Political Science 45 (1): 1-17.

Bollyky, Thomas J, Tara Templin, Matthew Cohen, Diana Schoder, Joseph L Dieleman, and Simon Wigley. 2019. "The Relationships Between Democratic Experience, Adult Health, 
and Cause-Specific Mortality in 170 Countries Between 1980 and 2016: An Observational Analysis." The Lancet 393 (10181): 1628-40.

Brennan, Geoffrey, and James M. Buchanan. 1980. The Power to Tax: Analytic Foundations of a Fiscal Constitution. New York: Cambridge University Press.

Carleton, Tamma, Jules Cornetet, Peter Huybers, Kyle Meng, and Jonathan Proctor. 2020. "Ultraviolet Radiation Decreases Covid-19 Growth Rates: Global Causal Estimates and Seasonal Implications." Working Paper. Available at SSRN 3588601.

Cepaluni, Gabriel, Michael Dorsch, and Reka Branyiczki. 2020. "Political Regimes and Deaths in the Early Stages of the COVID-19 Pandemic." \{SSRN Scholarly Paper\} ID 3586767. Rochester, NY: Social Science Research Network. https://doi.org/10.2139/ssrn.3586767. Chamorro-Premuzic, Tomas, and Avivah Wittenberg-Cox. 2020. "Will the Pandemic Reshape Notions of Female Leadership?" Harvard Business Review. https://hbr.org/2020/06/willthe-pandemic-reshape-notions-of-female-leadership.

Chattopadhyay, Raghabendra, and Esther Duflo. 2004. "Women as Policy Makers: Evidence from a Randomized Policy Experiment in India." Econometrica 72 (5): 1409-43.

Chigudu, Simukai. 2020. The Political Life of an Epidemic: Cholera, Crisis and Citizenship in Zimbabwe. New York: Cambridge University Press.

Clayton, Amanda, and Pär Zetterberg. 2018. "Quota Shocks: Electoral Gender Quotas and Government Spending Priorities Worldwide." The Journal of Politics 80 (3): 916-32.

Coscieme, Luca, Lorenzo Fioramonti, Lars F. Mortensen, Kate E. Pickett, Ida Kubiszewski, Hunter Lovins, Jacqueline Mcglade, et al. 2020. "Women in power: Female leadership and public health outcomes during the COVID-19 pandemic." medRxiv, 2020.07.13.20152397. https://doi.org/10.1101/2020.07.13.20152397.

D'Elia, Justine, and Helmut Norpoth. 2014. "Winning with a Bad Economy." Presidential Studies Quarterly 44 (3): 467-83.

Dassonneville, Ruth, and Michael S. Lewis-Beck. 2013. "Economic Policy Voting and Incumbency: Unemployment in Western Europe." Political Science Research and Methods $1(1): 53-66$.

Davis, Jennifer. 2004. "Corruption in Public Service Delivery: Experience from South Asia's Water and Sanitation Sector." World Development 32 (1): 53-71. 
Diaz-Cayeros, Alberto, Federico Estévez, and Beatriz Magaloni. 2016. The Political Logic of Poverty Relief: Electoral Strategies and Social Policy in Mexico. Cambridge University Press.

Dionne, Kim Yi. 2011. "The Role of Executive Time Horizons in State Response to AIDS in Africa." Comparative Political Studies 44 (1): 55-77.

Elgar, Frank J. 2010. "Income Inequality, Trust, and Population Health in 33 Countries." American Journal of Public Health 100 (11): 2311-15.

Elgar, Frank J., Anna Stefaniak, and Michael J. A. Wohl. 2020. "The trouble with trust: Timeseries analysis of social capital, income inequality, and COVID-19 deaths in 84 countries." Social Science $\mathscr{E}$ Medicine 263: 113365. https://doi.org/10.1016/j.socscimed.2020.113365. Englebert, Pierre. 2002. State Legitimacy and Development in Africa. Boulder, CO: Lynne Rienner Publishers.

Fearon, James D., and David D. Laitin. 1996. "Explaining Interethnic Cooperation." The American Political Science Review 90 (4): 715-35.

Feldman, Noah. 2020. "U.S. Federalism Isn’t Great at Handling Pandemics." Bloomberg.com, March. https://www.bloomberg.com/opinion/articles/2020-03-19/coronavirus-pandemicshows-challenges-of-u-s-federalism.

Fisman, Raymond, and Miriam A Golden. 2017. Corruption: What Everyone Needs to Know. Oxford University Press.

Fox, Justin. 2020. "What Prepares a Country for a Pandemic? An Epidemic Helps." https://www.bloomberg.com/opinion/articles/2020-03-18/covid-19-response-better-incountries-with-sars-mers-coronavirus.

Garikipati, Supriya, and Uma Kambhampati. 2021. "Leading the Fight Against the Pandemic: Does Gender Really Matter?" Feminist Economics 27 (1-2): 401-18.

Gächter, Simon, Benedikt Herrmann, and Christian Thöni. 2004. "Trust, Voluntary Cooperation, and Socio-Economic Background: Survey and Experimental Evidence." Journal of Economic Behavior \& Organization 55 (4): 505-31.

Ghobarah, Hazem Adam, Paul Huth, and Bruce Russett. 2004. "Comparative Public Health: The Political Economy of Human Misery and Well-Being." International Studies Quarterly 48 (1): 73-94. 
Gostin, Lawrence O., and James G. Hodge. 2020. "US Emergency Legal Responses to Novel Coronavirus: Balancing Public Health and Civil Liberties." Journal of the American Medical Association 323 (12): 1131-32.

Gugushvili, Alexi, Jonathan Koltai, David Stuckler, and Martin McKee. 2020. "Votes, Populism, and Pandemics." International Journal of Public Health 65 (6): 721-22.

Gupta, Sanjeev, Hamid Davoodi, and Erwin Tiongson. 2001. "Corruption and the Provision of Health Care and Education Services." In The Political Economy of Corruption, 123-53. Routledge.

Ha, Eunyoung, and Myung-koo Kang. 2015. "Government Policy Responses to Financial Crises: Identifying Patterns and Policy Origins in Developing Countries." World Development 68: 264-81.

Habyarimana, James, Macartan Humphreys, Daniel N. Posner, and Jeremy Weinstein. 2007. "Why Does Ethnic Diversity Undermine Public Goods Provision?" American Political Science Review 101 (4): 709-25.

Han, Qing, Bang Zheng, Mioara Cristea, Maximilian Agostini, Jocelyn J. Belanger, Ben Gutzkow, Jannis Kreienkamp, PsyCorona Collaboration, and N. Pontus Leander. 2021. "Trust in government regarding COVID-19 and its associations with preventive health behaviour and prosocial behaviour during the pandemic: a cross-sectional and longitudinal study." Psychological Medicine, 1-32. https://doi.org/10.1017/S0033291721001306.

Hicks, Alexander M., and Duane H. Swank. 1992. "Politics, Institutions, and Welfare Spending in Industrialized Democracies, 1960-82." The American Political Science Review $86(3): 658-74$.

ICG. 2020. "COVID-19 and Conflict: Seven Trends to Watch." ICG Special Briefing 4. https://www.crisisgroup.org/global/sb4-covid-19-and-conflict-seven-trends-watch.

Immergut, Ellen M. 1992. "The Rules of the Game: The Logic of Health Policy-Making in France, Switzerland, and Sweden." Structuring Politics: Historical Institutionalism in Comparative Analysis 4 (4): 57-89.

Iqbal, Zaryab, and Christopher Zorn. 2010. "Violent Conflict and the Spread of HIV/AIDS in Africa." The Journal of Politics 72 (1): 149-62.

Iversen, Torben, and David Soskice. 2006. "Electoral Institutions and the Politics of 
Coalitions: Why Some Democracies Redistribute More Than Others." American Political Science Review 100 (2): 165-81.

Iyer, Lakshmi, Anandi Mani, Prachi Mishra, and Petia Topalova. 2012. "The Power of Political Voice: Womens Political Representation and Crime in India." American Economic Journal: Applied Economics 4 (4): 165-93.

Jackson, Robert H, and Carl G Rosberg. 1982. "Why Africa's Weak States Persist: The Empirical and the Juridical in Statehood." World Politics 35 (1): 1-24.

Karabulut, Gokhan, Klaus F. Zimmermann, Mehmet Huseyin Bilgin, and Asli Cansin Doker. 2021. "Democracy and COVID-19 Outcomes." Economics Letters 203: 109840. https://doi.org/10.1016/j.econlet.2021.109840.

Karl, Terry Lynn. 1997. The Paradox of Plenty: Oil Booms and Petro-States. Vol. 26. University of California Press.

Kumar, Santosh, and Nishith Prakash. 2017. "Effect of Political Decentralization and Female Leadership on Institutional Births and Child Mortality in Rural Bihar, India." Social Science \& Medicine 185: 171-78.

Kyle, Jordan, and Brett Meyer. 2020. "High Tide? Populism in Power, 1990-2020." Working Paper. Tony Blair Institute.

Lake, David A, and Matthew A Baum. 2001. "The Invisible Hand of Democracy: Political Control and the Provision of Public Services." Comparative Political Studies 34 (6): $587-621$.

Larson, Jennifer M. 2017. "Networks and Interethnic Cooperation." The Journal of Politics $79(2): 546-59$.

Leigh, Andrew, Christopher Jencks, and Timothy M. Smeeding. 2009. "Health and economic inequality." In The Oxford Handbook of Economic Inequality, edited by Wiemer Salverda, Brian Nolan, and Timothy M. Smeeding, 384-405. New York: Oxford University Press. Lieberman, Evan S. 2007. "Ethnic Politics, Risk, and Policy-Making." Comparative Political Studies 40 (12): 1407-32.

- 2009. Boundaries of Contagion. Princeton, NJ: Princeton University Press.

McDonald, Michael D., Silvia M. Mendes, and Myunghee Kim. 2007. "Cross-Temporal and Cross-National Comparisons of Party Left-Right Positions." Electoral Studies 26 (1): 
$62-75$.

Mikkelsen, Lene, David E Phillips, Carla AbouZahr, Philip W Setel, Don De Savigny, Rafael Lozano, and Alan D Lopez. 2015. "A Global Assessment of Civil Registration and Vital Statistics Systems: Monitoring Data Quality and Progress." The Lancet 386 (10001): $1395-1406$.

Min, Jungwon. 2020. "Does social trust slow down or speed up the transmission of COVID19?" PLoS ONE 15 (12): e0244273. https://doi.org/10.1371/journal.pone.0244273.

Mounk, Yascha. 2021. "How Populism Has Proven Lethal in This Pandemic." Council on Foreign Relations. https://www.cfr.org/article/how-populism-has-proven-lethalpandemic.

Neyapti, Bilin. 2010. "Fiscal decentralization and deficits: International evidence." European Journal of Political Economy 26 (2): 155-66.

Nordhaus, William D. 1975. "The Political Business Cycle." The Review of Economic Studies 42 (2): 169-90.

Nunn, Nathan, and Leonard Wantchekon. 2011. "The Slave Trade and the Origins of Mistrust in Africa." American Economic Review 101 (7): 3221-52.

Oksanen, Atte, Markus Kaakinen, Rita Latikka, Iina Savolainen, Nina Savela, and Aki Koivula. 2020. "Regulation and Trust: 3-Month Follow-up Study on COVID-19 Mortality in 25 European Countries." JMIR Public Health and Surveillance 6 (2): e19218. https: //doi.org/10.2196/19218.

Oltermann, Philip. 2020. “Germany's Devolved Logic Is Helping It Win the Coronavirus Race." The Guardian, April. https://www.theguardian.com/world/2020/apr/05/germanysdevolved-logic-is-helping-it-win-the-coronavirus-race.

Paler, Laura. 2013. "Keeping the Public Purse: An Experiment in Windfalls, Taxes, and the Incentives to Restrain Government." American Political Science Review 107 (4): 706-25.

Parks, Craig D., Robert F. Henager, and Shawn D. Scamahorn. 1996. "Trust and Reactions to Messages of Intent in Social Dilemmas." Journal of Conflict Resolution 40 (1): 134-51.

Patterson, Amy. 2006. The Politics of AIDS in Africa. Boulder, CO: Lynne Rienner Publishers.

Persson, Torsten, and Guido Tabellini. 2000. Political Economics: Explaining Economic 
Policy. Cambridge, MA: The MIT Press.

Piscopo, Jennifer M. 2020. "Women Leaders and Pandemic Performance: A Spurious Correlation." Politics $\& 3$ Gender 16 (4): 951-59.

Reiter, Dan. 1995. "Political Structure and Foreign Policy Learning: Are Democracies More Likely to Act on the Lessons of History?" International Interactions 21 (1): 39-62.

Rode, Martin, and Julio Revuelta. 2015. "The Wild Bunch! An Empirical Note on Populism and Economic Institutions." Economics of Governance 16 (1): 73-96.

Ross, Michael. 2006. "Is Democracy Good for the Poor?" American Journal of Political Science 50 (4): 860-74.

Ross, Michael L. 2015. "What Have We Learned about the Resource Curse?" Annual Review of Political Science 18: 239-59.

Sánchez-Talanquer, Mariano, Eduardo González-Pier, Jaime Sepúlveda, Lucía Abascal-Miguel, and Jane Fieldhouse. 2021. "Mexico's Response to COVID-19: A Case Study." San Francisco, CA: University of California, San Francisco: Institute for Global Health Sciences. https://globalhealthsciences.ucsf.edu/sites/globalhealthsciences.ucsf.edu/files/mexicocovid-19-case-study-english.pdf.

Selway, Joel Sawat. 2015. Coalitions of the Well-Being: How Electoral Rules and Ethnic Politics Shape Health Policy in Developing Countries. New York: Cambridge University Press.

Sen, Amartya. 1982. Poverty and Famines: An Essay on Entitlement and Deprivation. New York: Oxford University Press.

Snyder Jr., James M., and David Strömberg. 2010. "Press Coverage and Political Accountability." Journal of Political Economy 118 (2): 355-408.

Strauss, Delphine. 2020. "Years of UK Jobs Growth Wiped out by Coronavirus." Financial Times. https://www.ft.com/content/9f3661b9-14cb-472a-9246-d784d436ea52.

Treisman, Daniel. 2002. "Decentralization and the Quality of Government." Working Paper. Los Angeles: Department of Political Science, UCLA.

Tsebelis, George. 2002. Veto Players: How Political Institutions Work. New York: Russell Sage Foundation.

Wang, Jingyuan, Ke Tang, Kai Feng, and Weifeng Lv. 2020. "High Temperature and High 
Humidity Reduce the Transmission of Covid-19." Working Paper. Available at SSRN $355176 \%$.

Weingast, Barry R. 1995. "The Economic Role of Political Institutions: Market-Preserving Federalism and Economic Development." Journal of Law, Economics, \&3 Organization 11 (1): $1-31$.

Wibbels, Erik. 2005. Federalism and the Market: Intergovernmental Conflict and Economic Reform in the Developing World. New York: Cambridge University Press.

Wynia, Matthew K. 2007. "Ethics and Public Health Emergencies: Restrictions on Liberty." The American Journal of Bioethics 7 (2): 1-5.

Zhou, Fei, Ting Yu, Ronghui Du, Guohui Fan, Ying Liu, Zhibo Liu, Jie Xiang, et al. 2020. "Clinical Course and Risk Factors for Mortality of Adult Inpatients with COVID-19 in Wuhan, China: A Retrospective Cohort Study." The Lancet 395 (10229): 1054-62. 


\section{SUPPLEMENTARY INFORMATION Political and Social Correlates of Covid-19 Mortality}

October 8, 2021

\section{Contents}

1 Measures and sources used in analysis 1

2 Summary statistics 2

3 Relationship between reported and excess deaths $\quad 3$

4 Description of Lasso procedure $\quad 3$

5 Summary of strongest predictors $\quad 5$

6 Detailed results for main models with controls $\quad 5$

7 Patterns for countries with per capita income below $\$ 20,000 \quad 9$

8 Probing into the impact of trust $\quad 10$

9 Results from analyses using fixed effects $\quad 10$

10 Results from analyses using alternative Lasso controls $\quad 10$

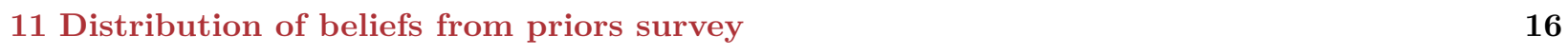

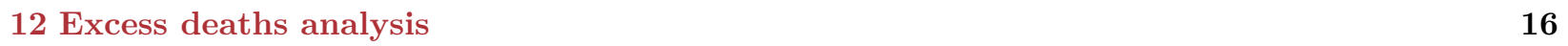

13 Expert survey $\quad 18$

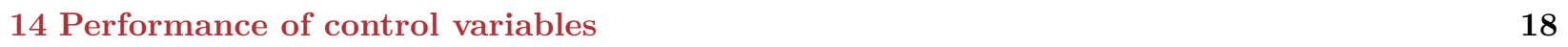

15 Machine learning $\quad 18$ 


\section{Measures and sources used in analysis}

Table 1 on page 1 presents the measures used in the analyses reported in the manuscript, as well as the data sources. Measures are grouped based on the family of explanations they are part of, and mirror the presentation adopted in the Literature Review section. Summary statistics for these indicators are given in Table 2 on page 2.

\begin{tabular}{|c|c|c|}
\hline Label & Data source & Short definition \\
\hline \multicolumn{3}{|l|}{ 1.1. General capacity } \\
\hline Government effectiveness & $\begin{array}{l}\text { World Bank Indica- } \\
\text { tors }\end{array}$ & $\begin{array}{l}\text { Perceived quality of public services, its provision and } \\
\text { providers. }\end{array}$ \\
\hline State fragility & $\begin{array}{l}\text { State Fragility In- } \\
\text { dex }\end{array}$ & $\begin{array}{l}\text { (In)capacity to provide essential public goods, services } \\
\text { and to cope with shocks. }\end{array}$ \\
\hline Public sector corruption & $\begin{array}{l}\text { V-Dem Dataset - } \\
\text { Version } 10\end{array}$ & $\begin{array}{l}\text { Pervasiveness of bureaucratic corruption in the public } \\
\text { sector. }\end{array}$ \\
\hline Institutional trust & WVS, LAPOP & $\begin{array}{l}\text { Percentage of respondents who reported trusting the } \\
\text { government. }\end{array}$ \\
\hline \multicolumn{3}{|l|}{ 1.2. Sector-specific capacity } \\
\hline Ebola/SARS/MERS exposure & WHO (HDX) & $\begin{array}{l}\text { Whether a country experienced at least } 100 \text { cases for } \\
\text { MERS, SARS, or Ebola. }\end{array}$ \\
\hline Pandemic preparedness & GHSI 2019 & $\begin{array}{l}\text { Capacity to prevent, detect and respond rapidly to } \\
\text { disease outbreaks. }\end{array}$ \\
\hline \multicolumn{3}{|l|}{ 2.1. Centralization } \\
\hline Veto players & DPI 2017 & $\begin{array}{l}\text { Extent to which a government is subject of checks } \\
\text { and balances. }\end{array}$ \\
\hline Index of federalism & DPI 2017 & $\begin{array}{l}\text { Extent to which power and decision making processes } \\
\text { are decentralized. }\end{array}$ \\
\hline \multicolumn{3}{|l|}{ 2.2. Political responsiveness } \\
\hline Liberal democracy & $\begin{array}{l}\text { V-Dem Dataset - } \\
\text { Version } 10\end{array}$ & $\begin{array}{l}\text { Extent to which the ideal of a liberal democracy is } \\
\text { achieved. }\end{array}$ \\
\hline PR electoral system & DPI 2017 & $\begin{array}{l}\text { Whether candidates are elected based on the vote } \\
\text { share received by their party. }\end{array}$ \\
\hline Media independence & $\begin{array}{l}\text { V-Dem Dataset - } \\
\text { Version } 10\end{array}$ & $\begin{array}{l}\text { Extent to which i.a. journalists accept payments in } \\
\text { exchange for altering news coverage. }\end{array}$ \\
\hline Oil rents ( $\%$ of GDP) & $\begin{array}{l}\text { World Bank Indica- } \\
\text { tors }\end{array}$ & Oil rents as a share of GDP. \\
\hline \multicolumn{3}{|l|}{ 3. Political priorities } \\
\hline Electoral populism & Populism in Power & $\begin{array}{l}\text { Whether a democratically elected head of government } \\
\text { ran a populist campaign. }\end{array}$ \\
\hline Women leas & Wikipedia list & A woman was head of government on $1 / 1 / 2020$. \\
\hline Electoral pressure & $\begin{array}{l}\text { IFES, IPU, } \\
\text { Wikipedia list }\end{array}$ & $\begin{array}{l}\text { Days to the next parliamentary, presidential or senate } \\
\text { election counted from } 11 \text { Mar } 2020 .\end{array}$ \\
\hline \multicolumn{3}{|l|}{ 4. Social structures } \\
\hline Ethnic fractionalization & $\begin{array}{l}\text { Alesina } \quad \text { et } \quad \text { al. } \\
\text { (QoG) }\end{array}$ & $\begin{array}{l}\text { Probability two random people from a given country } \\
\text { are not of the same ethnic group. }\end{array}$ \\
\hline Religious fractionalization & $\begin{array}{l}\text { Alesina et al. } \\
\text { (QoG) }\end{array}$ & $\begin{array}{l}\text { Probability two random people from a given country } \\
\text { are not of the same religious group. }\end{array}$ \\
\hline Income GINI & SWIID v8.2 & $\begin{array}{l}\text { Dispersion of post-tax and transfer income among } \\
\text { the citizens of a country. }\end{array}$ \\
\hline
\end{tabular}

Table 1: Measures and sources 


\section{Summary statistics}

Table 2 presents a few summary statistics for the set of theoretically-relevant covariates that our analysis includes, along with the Lasso-derived controls we rely on in all multivariate analyses. Sample sizes are around 140-150, with the exception of indicators derived directly from individual-level surveys: our two measures of trust.

\begin{tabular}{|c|c|c|c|c|c|c|}
\hline Variable & Mean & Median & SD & Min & Max & $\mathrm{N}$ \\
\hline \multicolumn{7}{|l|}{ Covid deaths } \\
\hline Deaths/million (May 30) & 719.62 & 321.14 & 902.26 & 0.37 & 6045.44 & 154 \\
\hline \multicolumn{7}{|l|}{ Base controls } \\
\hline Healthcare quality index (GHSI) & 60.70 & 64.30 & 22.84 & 18.60 & 96.60 & 151 \\
\hline Healthcare spending/capita & 991.68 & 412.00 & 1389.61 & 4.00 & 8078.00 & 148 \\
\hline Life expectancy & 71.80 & 73.78 & 8.03 & 52.24 & 84.10 & 154 \\
\hline Respiratory disease prevalence & 3.42 & 3.41 & 0.65 & 1.61 & 4.92 & 153 \\
\hline Health data quality (GHSI) & 47.95 & 44.60 & 22.83 & 2.70 & 98.20 & 151 \\
\hline \multicolumn{7}{|l|}{ 1.1. General capacity } \\
\hline Government effectiveness & -0.10 & -0.24 & 1.00 & -2.45 & 2.23 & 154 \\
\hline State fragility & 8.10 & 7.50 & 6.21 & 0.00 & 24.00 & 152 \\
\hline Public sector corruption & 0.49 & 0.51 & 0.29 & 0.01 & 0.97 & 152 \\
\hline Institutional trust & 41.92 & 39.06 & 23.35 & 5.14 & 97.14 & 78 \\
\hline \multicolumn{7}{|l|}{ 1.2. Sector-specific capacity } \\
\hline Pandemic preparedness & 43.29 & 41.30 & 14.55 & 16.20 & 83.50 & 151 \\
\hline Ebola/SARS/MERS exposure & 0.05 & 0.00 & 0.21 & 0.00 & 1.00 & 154 \\
\hline \multicolumn{7}{|l|}{ 2.1. Centralization } \\
\hline Veto players & 2.85 & 3.00 & 1.38 & 1.00 & 7.00 & 143 \\
\hline Index of federalism & 0.03 & -0.07 & 0.67 & -1.03 & 1.51 & 116 \\
\hline \multicolumn{7}{|l|}{ 2.2. Political responsiveness } \\
\hline Liberal democracy & 0.42 & 0.38 & 0.26 & 0.04 & 0.88 & 151 \\
\hline PR electoral system & 0.66 & 1.00 & 0.47 & 0.00 & 1.00 & 140 \\
\hline Media independence & 2.49 & 2.61 & 0.99 & 0.20 & 3.96 & 151 \\
\hline Oil rents (\% of GDP) & 2.89 & 0.03 & 7.39 & 0.00 & 37.52 & 150 \\
\hline \multicolumn{7}{|l|}{ 3. Political priorities } \\
\hline Electoral populism & 0.11 & 0.00 & 0.31 & 0.00 & 1.00 & 154 \\
\hline Women leaders & 0.08 & 0.00 & 0.27 & 0.00 & 1.00 & 154 \\
\hline Electoral pressure & 802.66 & 690.00 & 563.48 & 16.00 & 2054.00 & 154 \\
\hline \multicolumn{7}{|l|}{ 4. Social structures } \\
\hline Ethnic fractionalization & 0.46 & 0.49 & 0.25 & 0.00 & 0.93 & 146 \\
\hline Religious fractionalization & 0.43 & 0.45 & 0.23 & 0.00 & 0.86 & 147 \\
\hline Income GINI & 38.54 & 38.33 & 7.90 & 23.68 & 65.11 & 137 \\
\hline Interpersonal trust & 21.83 & 17.83 & 14.71 & 2.14 & 73.73 & 106 \\
\hline
\end{tabular}

Table 2: Summary statistics 


\section{Relationship between reported and excess deaths}

Figure 1 reports the correlation between reported deaths (obtained from the ECDC) and excess deaths (obtained from the repository maintained by The Economist magazine). The correlation indicates a reasonably strong relationship, though we clearly see cases that don't fit the linear patterns, such as Armenia, Azerbaijan, Lithuania, Mexico, North Macedonia, Peru, Russia, South Africa, or Serbia.

Figure 1: Association between reported deaths and excess deaths

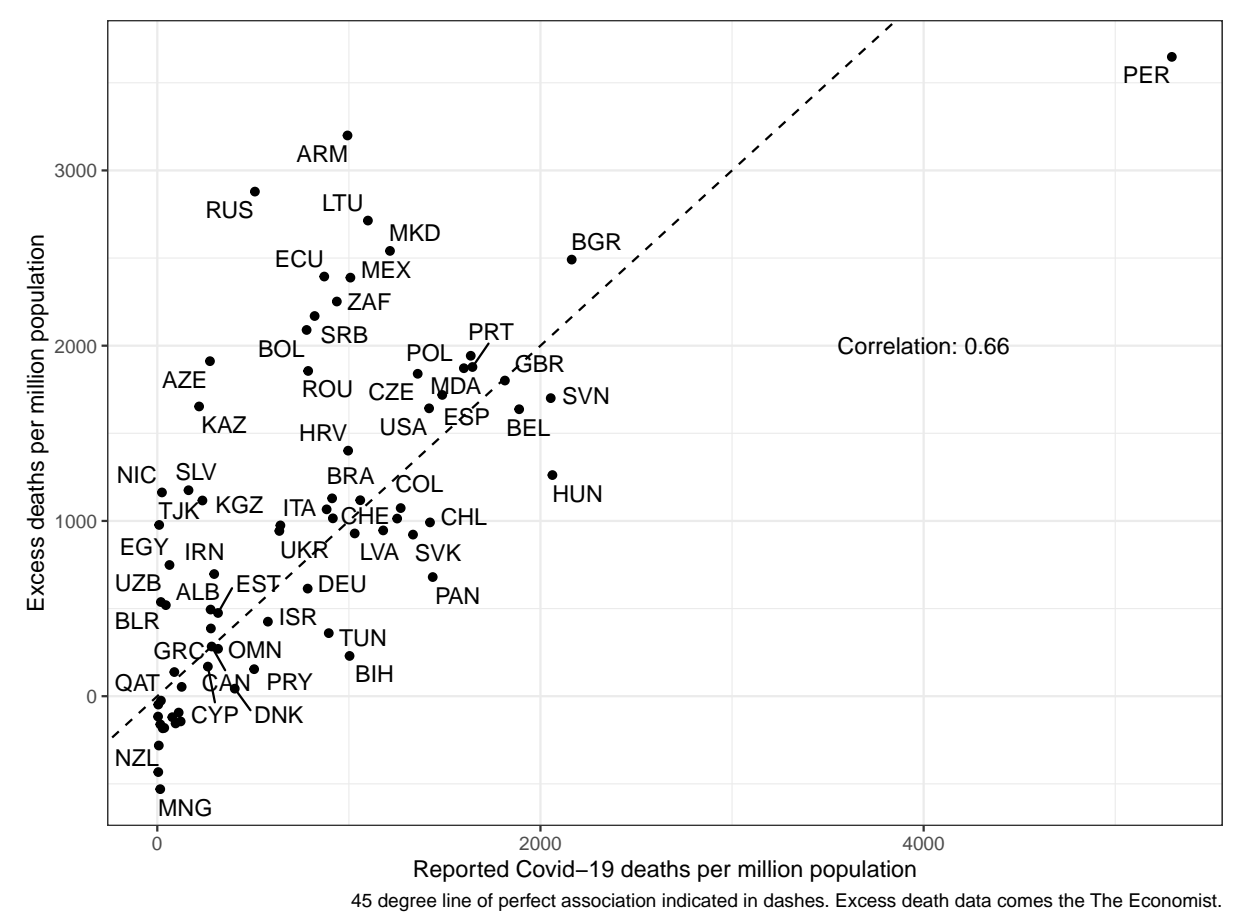

\section{Description of Lasso procedure}

The Lasso helps us select a small set of non-political base covariates that minimize the cross-validated out-of-sample prediction error of a linear model. We list the candidate variables in Table 3 on page 4 . The top four variables selected by this procedure vary depending on what day's data is used. For this paper we have selected controls using data from May 15, 2020. The variables selected are: an index of healthcare quality, the prevalence of respiratory diseases in the country, life expectancy, and healthcare spending per capita. These four variables are always included when we report conditional correlations between social and political factors and per capita Covid-19 deaths.

In addition to the Lasso-derived controls, we also always include an index of the quality of early detection and reporting of epidemics. We include this index due to its intuitive appeal in accounting for measurement concerns around reporting of deaths. According to the Global Health Security Index (GHSI), the indicators used to construct this index assess "laboratory systems; real-time surveillance and reporting; epidemiology workforce; and data integration between the human, animal, and environmental health sectors." Figure 8 on page 19 shows how these controls perform in predicting out-of-sample per-capita mortality. 


\begin{tabular}{|c|c|c|}
\hline Label & Data source & Short definition \\
\hline HDI & UNDP via GHSI & $\begin{array}{l}\text { Summary measure of achievement in key dimensions of human development: } \\
\text { life expectancy and health, knowledgeable and standards of living. }\end{array}$ \\
\hline GDP per capita (PPP) & World Bank & GDP per capita, PPP (constant 2011 international $\$$ ) \\
\hline Trade (share of GDP) & World Bank & Sum of exports and imports of goods and services as a share of GDP \\
\hline FDI (net inflows, USD) & World Bank & Foreign direct investment, net inflows (Current US\$) \\
\hline Population density (log) & FAO and World Bank & Population density (people per sq. $\mathrm{km}$ of land area) \\
\hline Total population (logged) & World Bank & Total population (In '000,000) \\
\hline Precipitation (mm/month) & $\begin{array}{l}\text { Climatic Research Unit, } \\
\text { University of East Anglia }\end{array}$ & $\begin{array}{l}\text { Average cumulative precipitation starting from January 2020, in mm per } \\
\text { month }\end{array}$ \\
\hline Temperature (Celsius) & $\begin{array}{l}\text { Climatic Research Unit, } \\
\text { University of East Anglia }\end{array}$ & $\begin{array}{l}\text { Average cumulative temperature starting from January 2020, in Celsius } \\
\text { degrees }\end{array}$ \\
\hline Share $65+$ & World Bank & Share of population older than 65 years \\
\hline Respiratory disease prevalence & $\begin{array}{l}\text { Institute for Health Metrics and } \\
\text { Evaluation (IHME) }\end{array}$ & Prevalance of upper and lower respiratory disease in 2017. \\
\hline Life expectancy & World Bank & Life expectancy at birth \\
\hline Share with health insurance & ILO via Our World in Data & Sahre of population with insurance coverage \\
\hline Hospital beds / capita (GHSI) & GHSI & Hospital beds per capita. \\
\hline Health data quality & GHSI & Index of early detection and reporting of epidemics. \\
\hline Health sector robustness (GHSI) & GHSI & Index reporting on sufficient and robust health sector. \\
\hline Healthcare quality index (GHSI) & GHSI & $\begin{array}{l}\text { Index based on mortality from causes amenable to personal health care } \\
(0-100) \text {. }\end{array}$ \\
\hline Healthcare spending/capita & GHSI & Healthcare spending/capita \\
\hline
\end{tabular}

Table 3: Set of potential base covariates. 


\section{$5 \quad$ Summary of strongest predictors}

Table 4 presents estimates from a multivariate analysis of log per capita Covid-19 deaths. In this table, we list all predictors with associations significant at $\alpha=0.1$ after adjusting for multiple comparisons. For the full set of results see Section 6 .

\begin{tabular}{lrr}
\hline Variable & Estimate & $\mathrm{P}$ (adj.) \\
\hline Interpersonal trust & -0.96 & 0.00 \\
Institutional trust & -0.91 & 0.00 \\
State fragility & -0.57 & 0.01 \\
Ebola/SARS/MERS exposure & -0.39 & 0.02 \\
Media independence & 0.29 & 0.09 \\
PR electoral system & 0.33 & 0.04 \\
Income GINI & 0.37 & 0.04 \\
Liberal democracy & 0.44 & 0.03 \\
\hline
\end{tabular}

Table 4: Strongest predictors summary

\section{Detailed results for main models with controls}

The following sets of tables (Table 5, Table 6 on page 6 , Table 7 on page 7 , and Table 8 on page 8) show detailed results that are also presented in graphical format in Figure 4 in the manuscript. We present $p$ values both in unadjusted form, and with adjustment for multiple comparisons. Estimates are produced for weekly data reported on (1) June 1, 2020; (2) October 5, 2020; (3) February 8, 2021; and (4) June 28, 2021.

\begin{tabular}{|c|c|c|c|c|}
\hline Variable & Estimate & $\mathrm{P}$ & $\mathrm{P}$ (adj.) & $\mathrm{N}$ \\
\hline \multicolumn{5}{|l|}{ 1.1. General capacity } \\
\hline Government effectiveness & -0.61 & 0.01 & 0.01 & 148 \\
\hline State fragility & -0.19 & 0.35 & 0.35 & 148 \\
\hline Public sector corruption & 0.28 & 0.09 & 0.10 & 148 \\
\hline Institutional trust & -0.66 & 0.00 & 0.00 & 75 \\
\hline \multicolumn{5}{|l|}{ 1.2. Sector specific capacity } \\
\hline Ebola/SARS/MERS exposure & -0.08 & 0.56 & 0.75 & 148 \\
\hline Pandemic preparedness & 0.32 & 0.43 & 0.75 & 148 \\
\hline \multicolumn{5}{|l|}{ 2.1. Centralization } \\
\hline Veto players & 0.26 & 0.06 & 0.08 & 140 \\
\hline Index of federalism & 0.08 & 0.60 & 0.60 & 115 \\
\hline \multicolumn{5}{|l|}{ 2.2. Pol. responsiveness } \\
\hline Liberal democracy & 0.17 & 0.27 & 0.38 & 148 \\
\hline PR electoral system & 0.18 & 0.15 & 0.29 & 139 \\
\hline Media independence & 0.08 & 0.49 & 0.49 & 148 \\
\hline Oil rents (\% of GDP) & -0.10 & 0.28 & 0.38 & 146 \\
\hline \multicolumn{5}{|l|}{ 3. Pol. priorities } \\
\hline Electoral populism & 0.07 & 0.50 & 0.75 & 148 \\
\hline Women leaders & -0.03 & 0.83 & 0.95 & 148 \\
\hline Electoral pressure & -0.12 & 0.25 & 0.51 & 148 \\
\hline \multicolumn{5}{|l|}{ 4. Social structures } \\
\hline Ethnic fractionalization & 0.24 & 0.15 & 0.17 & 143 \\
\hline Religious fractionalization & -0.28 & 0.03 & 0.06 & 144 \\
\hline Income GINI & 0.27 & 0.11 & 0.14 & 134 \\
\hline Interpersonal trust & -0.43 & 0.01 & 0.03 & 103 \\
\hline
\end{tabular}

Note: The table shows estimates, raw p-values and p-values adjusted for multiple comparisons (Benjamini-Hochberg procedure). All variables are standardized. All models include the controls listed in the text. The outcome is the logarithm of the number of deaths per one million population, as of June 1, 2020.

Table 5: Estimates and p-values: log deaths / capita, June 2020 


\begin{tabular}{llrrr}
\hline Variable & Estimate & $\mathrm{P}$ & $\mathrm{P}$ (adj.) & $\mathrm{N}$ \\
\hline 1.1. General capacity & & & & \\
\hline Government effectiveness & -0.68 & 0.02 & 0.02 & 148 \\
State fragility & -0.23 & 0.33 & 0.34 & 148 \\
Public sector corruption & 0.19 & 0.34 & 0.34 & 148 \\
Institutional trust & -0.85 & 0.00 & 0.00 & 75 \\
1.2. Sector specific capacity & & & & \\
\hline Ebola/SARS/MERS exposure & -0.21 & 0.17 & 0.22 & 148 \\
Pandemic preparedness & 0.23 & 0.63 & 0.63 & 148 \\
2.1. Centralization & & & & \\
\hline Veto players & 0.27 & 0.07 & 0.09 & 140 \\
Index of federalism & 0.08 & 0.65 & 0.65 & 115 \\
2.2. Pol. responsiveness & & & & \\
\hline Liberal democracy & 0.22 & 0.21 & 0.33 & 148 \\
PR electoral system & 0.25 & 0.07 & 0.14 & 139 \\
Media independence & 0.11 & 0.46 & 0.62 & 148 \\
Oil rents (\% of GDP) & -0.01 & 0.94 & 0.94 & 146 \\
3. Pol. priorities & & & & \\
\hline Electoral populism & & & & \\
Women leaders & 0.16 & 0.26 & 0.40 & 148 \\
Electoral pressure & -0.03 & 0.84 & 0.84 & 148 \\
4. Social structures & -0.14 & 0.27 & 0.40 & 148 \\
\hline Ethnic fractionalization & & & & \\
Religious fractionalization & 0.15 & 0.40 & 0.40 & 143 \\
Income GINI & -0.32 & 0.04 & 0.06 & 144 \\
Interpersonal trust & 0.36 & 0.06 & 0.07 & 134 \\
\hline Note: The tableshown & -0.77 & 0.00 & 0.00 & 103 \\
\hline
\end{tabular}

Note: The table shows estimates, raw p-values and p-values adjusted for multiple comparisons (Benjamini-Hochberg procedure). All variables are standardized. All models include the controls listed in the text. The outcome is the logarithm of the number of deaths per one million population, as of October 5, 2020.

Table 6: Estimates and p-values: log deaths / capita, October 2020 


\begin{tabular}{lllrr}
\hline Variable & Estimate & $\mathrm{P}$ & $\mathrm{P}$ (adj.) & $\mathrm{N}$ \\
\hline 1.1. General capacity & & & & \\
\hline Government effectiveness & -0.38 & 0.21 & 0.24 & 148 \\
State fragility & -0.52 & 0.02 & 0.03 & 148 \\
Public sector corruption & -0.06 & 0.75 & 0.75 & 148 \\
Institutional trust & -0.94 & 0.00 & 0.00 & 75 \\
1.2. Sector specific capacity & & & & \\
\hline Ebola/SARS/MERS exposure & -0.36 & 0.02 & 0.03 & 148 \\
Pandemic preparedness & -0.14 & 0.78 & 0.78 & 148 \\
2.1. Centralization & & & & \\
\hline Veto players & 0.32 & 0.05 & 0.07 & 140 \\
Index of federalism & 0.16 & 0.36 & 0.36 & 115 \\
2.2. Pol. responsiveness & & & & \\
\hline Liberal democracy & 0.53 & 0.01 & 0.01 & 148 \\
PR electoral system & 0.37 & 0.02 & 0.02 & 139 \\
Media independence & 0.35 & 0.02 & 0.02 & 148 \\
Oil rents (\% of GDP) & -0.11 & 0.35 & 0.35 & 146 \\
3. Pol. priorities & & & & \\
\hline Electoral populism & 0.15 & 0.23 & 0.47 & 148 \\
Women leaders & -0.04 & 0.79 & 0.89 & 148 \\
Electoral pressure & -0.11 & 0.39 & 0.59 & 148 \\
4. Social structures & & & & \\
\hline Ethnic fractionalization & 0.04 & 0.84 & 0.84 & 143 \\
Religious fractionalization & -0.21 & 0.18 & 0.24 & 144 \\
Income GINI & 0.36 & 0.04 & 0.08 & 134 \\
Interpersonal trust & -0.92 & 0.00 & 0.00 & 103 \\
\hline Note: & & & &
\end{tabular}

Note:

The table shows estimates, raw p-values and p-values adjusted for multiple comparisons (BenjaminiHochberg procedure). All variables are standardized. All models include the controls listed in the text. The outcome is the logarithm of the number of deaths per one million population, as of February 8, 2021.

Table 7: Estimates and p-values: log deaths / capita, February 2021 


\begin{tabular}{llrrr}
\hline Variable & Estimate & $\mathrm{P}$ & $\mathrm{P}$ (adj.) & $\mathrm{N}$ \\
\hline 1.1. General capacity & & & & \\
\hline Government effectiveness & -0.37 & 0.24 & 0.28 & 148 \\
State fragility & -0.57 & 0.01 & 0.01 & 148 \\
Public sector corruption & -0.01 & 0.97 & 0.97 & 148 \\
Institutional trust & -0.91 & 0.00 & 0.00 & 75 \\
1.2. Sector specific capacity & & & & \\
\hline Ebola/SARS/MERS exposure & -0.39 & 0.02 & 0.02 & 148 \\
Pandemic preparedness & -0.07 & 0.85 & 0.85 & 148 \\
2.1. Centralization & & & & \\
\hline Veto players & 0.25 & 0.10 & 0.13 & 140 \\
Index of federalism & 0.10 & 0.54 & 0.54 & 115 \\
2.2. Pol. responsiveness & & & & \\
\hline Liberal democracy & 0.44 & 0.01 & 0.03 & 148 \\
PR electoral system & 0.33 & 0.03 & 0.04 & 139 \\
Media independence & 0.29 & 0.06 & 0.09 & 148 \\
Oil rents (\% of GDP) & -0.05 & 0.59 & 0.59 & 146 \\
3. Pol. priorities & & & & \\
\hline Electoral populism & 0.18 & 0.14 & 0.43 & 148 \\
Women leaders & -0.07 & 0.67 & 0.81 & 148 \\
Electoral pressure & -0.11 & 0.41 & 0.61 & 148 \\
4. Social structures & & & & \\
\hline Ethnic fractionalization & 0.06 & 0.70 & 0.70 & 143 \\
Religious fractionalization & -0.22 & 0.14 & 0.19 & 144 \\
Income GINI & 0.37 & 0.02 & 0.04 & 134 \\
Interpersonal trust & -0.96 & 0.00 & 0.00 & 103 \\
\hline Note: & & & &
\end{tabular}

Note:

The table shows estimates, raw p-values and p-values adjusted for multiple comparisons (BenjaminiHochberg procedure). All variables are standardized. All models include the controls listed in the text. The outcome is the logarithm of the number of deaths per one million population, as of June $28,2021$.

Table 8: Estimates and p-values: log deaths / capita, June 2021 


\section{Patterns for countries with per capita income below $\$ 20,000$}

Figure 2 replicates our main analysis on a sample made up only of lower-income countries (with a GDP/capita below USD 20,000). Though some change in the estimates is visible and expected, given the sample truncation, we point here to the impressive stability. Both our indicators for institutional and interpersonal trust remain significant for most time periods, as do those for liberal democracy and a PR electoral system in the last two time periods.

Figure 2: Correlates of Covid-19 outcomes: restricted to countries with GDP/capita below USD 20,000.

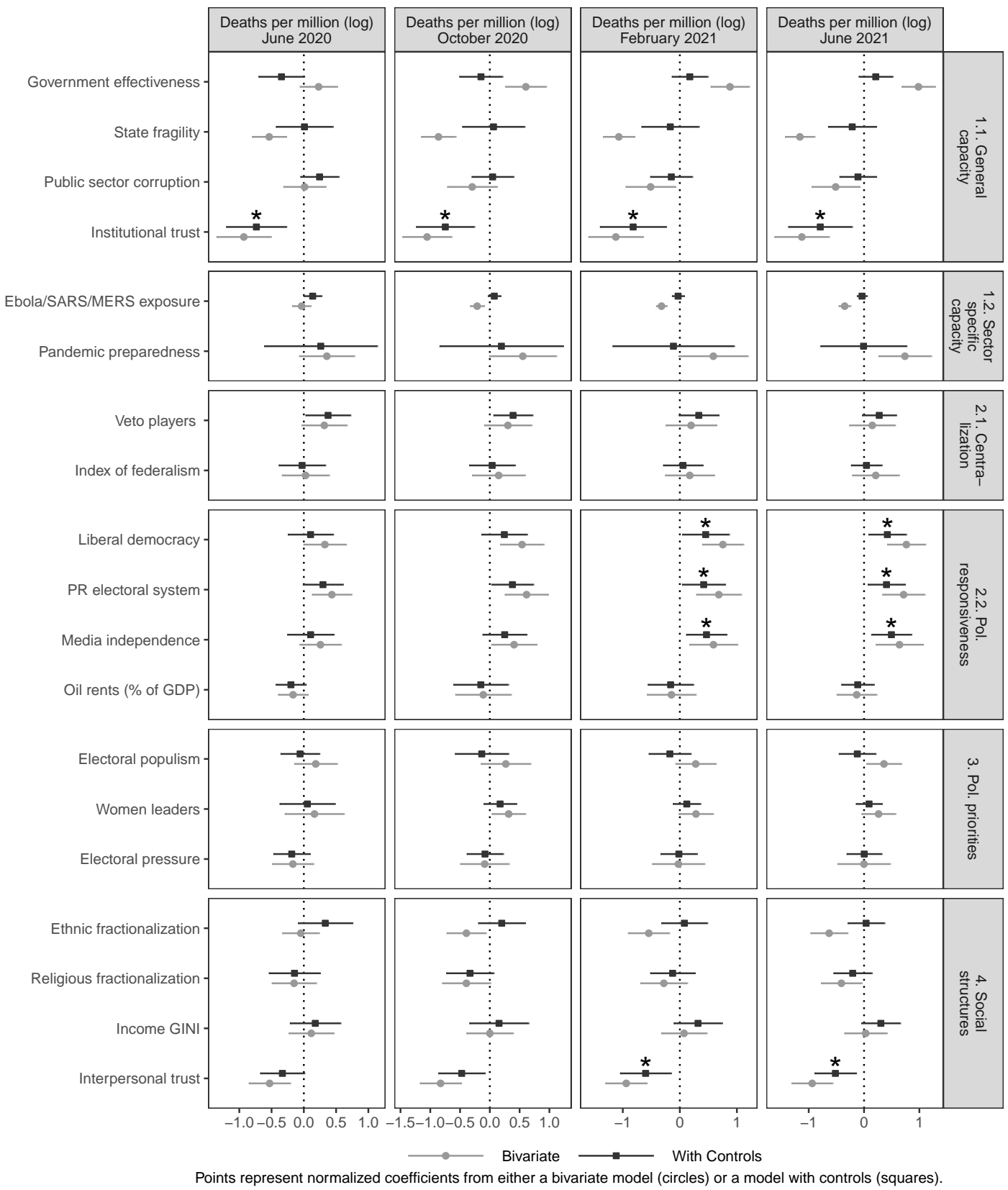




\section{Probing into the impact of trust}

Table 9 displays estimates from a set of simple linear specifications that explain Covid-19 mortality (logged per capita) using the two trust indicators in our data: institutional and interpersonal (social). We can easily see that both are negatively and strongly associated with Covid-19 mortality (Models 1 and 2). Including both in a specification results in a minimal degree of suppression: both continue to be negatively associated with reported mortality (Model 3). We do not detect any interaction at play, according to the evidence in Model 4.

\begin{tabular}{lcccc}
\hline & Model 1 & Model 2 & Model 3 & Model 4 \\
\hline Social trust & $-0.96^{* * *}$ & & $-0.79^{* *}$ & $-0.79^{* *}$ \\
& $(0.19)$ & & $(0.28)$ & $(0.28)$ \\
Institutional trust & & $-0.91^{* * *}$ & $-0.76^{* * *}$ & $-0.80^{* * *}$ \\
& & $(0.21)$ & $(0.19)$ & $(0.21)$ \\
Interaction & & & & -0.24 \\
& & & & $(0.40)$ \\
\hline $\mathrm{R}^{2}$ & 0.49 & 0.37 & 0.47 & 0.48 \\
Adj. $\mathrm{R}^{2}$ & 0.45 & 0.31 & 0.41 & 0.41 \\
Num. obs. & 103 & 75 & 68 & 68 \\
RMSE & 1.46 & 1.45 & 1.38 & 1.39 \\
\hline$* * *$ & & & \\
Lasso controls included in the specification, but omitted from the table. \\
All predictors have been centered and standardized. Robust standard errors used.
\end{tabular}

Table 9: Linear models of Covid-19 mortality: impact of trust indicators

\section{Results from analyses using fixed effects}

The figures below present results obtained by adding fixed effects for continents to the analyses we present in the main body of the paper. Figure 4 on page 12 shows the out of sample predictions from our analysis, which now includes fixed effects. Figure 3 on page 11 shows the associations between the Covid-19 correlates included in our theoretical families, and the outcome used in the main analysis: logged reported deaths per one million population. We choose here the same logic used in the main body of the paper - showing the statistical associations, with and without controls, for four distinct periods of time, roughly equally spaced along the course of the pandemic: June and October 2020, and February and June, 2021.

A cursory look at Figure 3, and especially the most recent set of results from June 2021, reveals that the fixed effects do not greatly impact our core conclusions. Though in the FE specification income inequality and a PR electoral system are no longer statistically significant (when compared to the results in Figure 4 in the manuscript), while media independence has a significant estimate, the direction and general magnitude of the estimates is preserved. All other predictors, for which we identified a consistent effect in our main analysis, continue to be statistically significant in this specification as well: institutional and interpersonal trust, past epidemic exposure, or liberal democracy.

\section{Results from analyses using alternative Lasso controls}


Figure 3: Correlates of Covid-19 outcomes from analysis including fixed effects

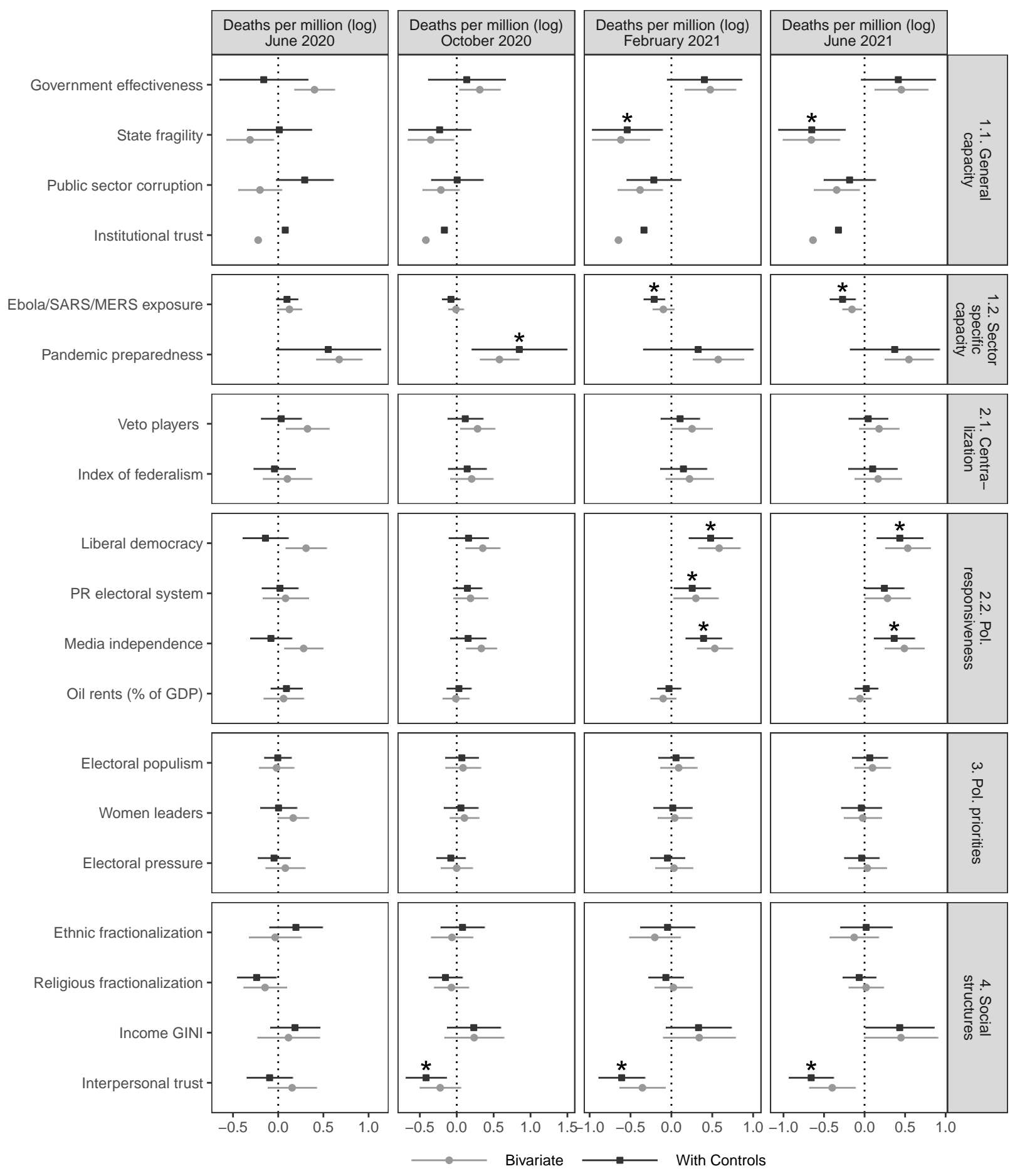

Points represent normalized coefficients from either a bivariate model (circles) or a model with controls (squares). 
Figure 4: Out of sample predictions from controls, based on analysis that includes fixed effects for continents

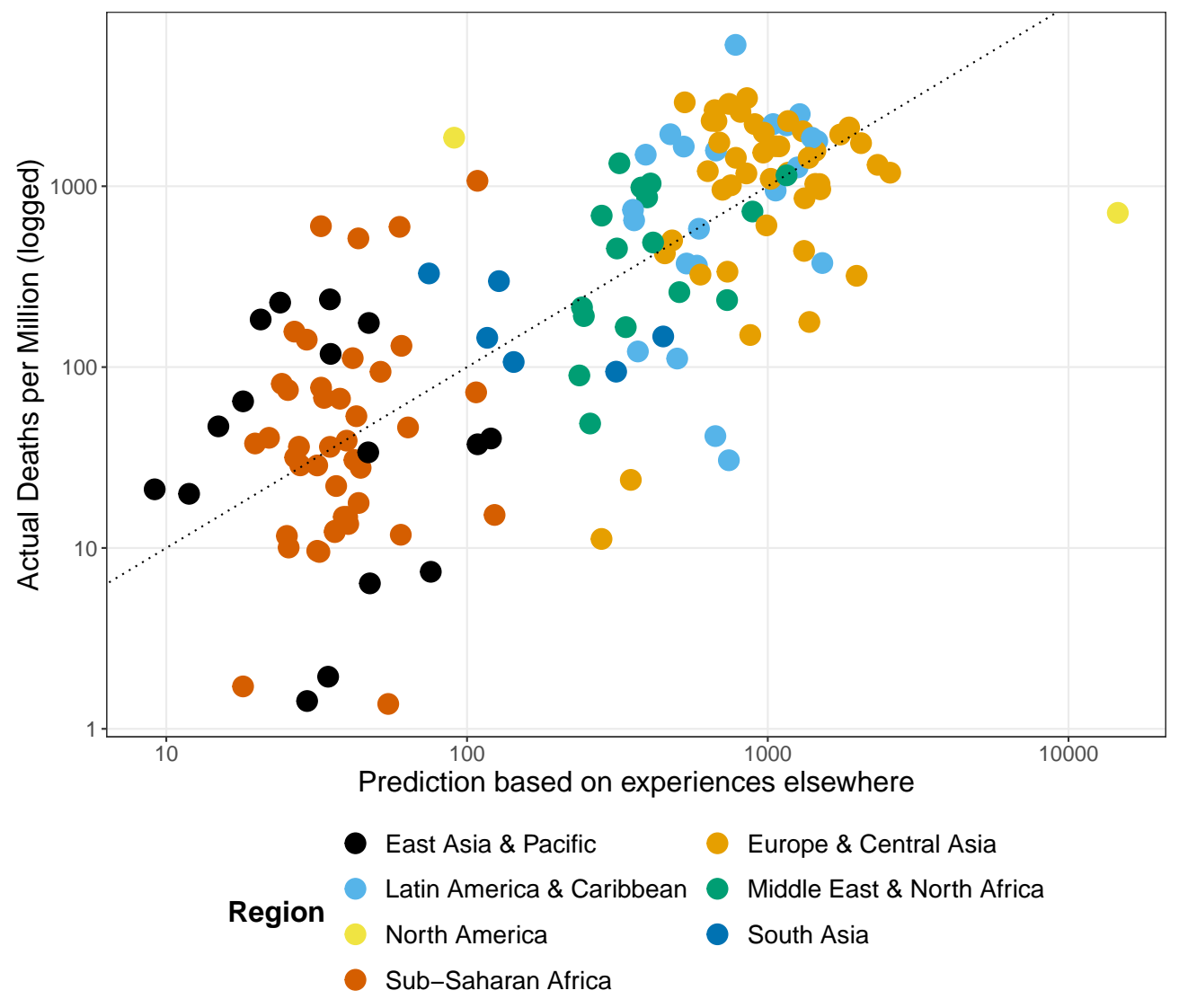

Points above (below) the 45 degree line do worse (better) than predicted.

\begin{tabular}{lrr}
\hline labels & estimate & p.value.adj \\
\hline Interpersonal trust & -1.03 & 0.00 \\
Institutional trust & -1.03 & 0.00 \\
State fragility & -0.58 & 0.00 \\
Ebola/SARS/MERS exposure & -0.37 & 0.02 \\
PR electoral system & 0.30 & 0.06 \\
Liberal democracy & 0.46 & 0.05 \\
Income GINI & 0.63 & 0.00 \\
\hline
\end{tabular}

Table 10: Strongest predictors summary with alternative Lasso controls 
Figure 5: Correlates of Covid-19 outcomes: alternative controls

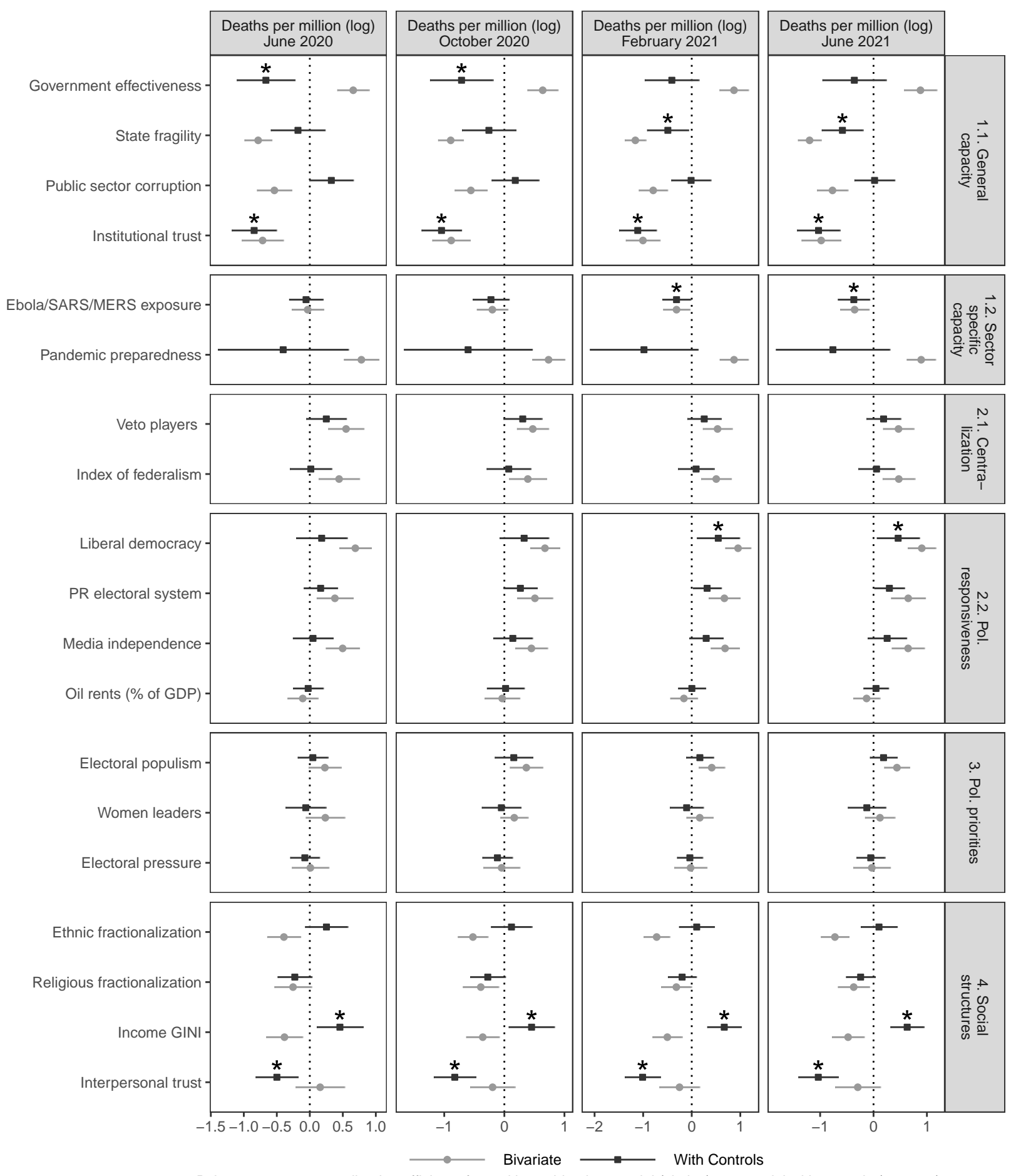

Points represent normalized coefficients from either a bivariate model (circles) or a model with controls (squares). 
Table 11: Causal mechanisms from our political and social factors to Covid-19 mortality

\begin{tabular}{|c|c|c|}
\hline Factors & Potential mechanisms & $\begin{array}{ll}\text { Effects } & \text { on } \\
\text { mortality } & \end{array}$ \\
\hline \multirow{3}{*}{ Veto players } & Consensual decision-making $\Rightarrow$ Policy stability & + \\
\hline & Higher legitimacy $\Rightarrow$ Higher rule compliance and support & - \\
\hline & More bureaucratic autonomy $\Rightarrow$ Faster government response & - \\
\hline \multirow{3}{*}{ State fragility } & Lower state capacity $\Rightarrow$ Poorer policy implementation & + \\
\hline & Lower state capacity $\Rightarrow$ Lower public goods provision & + \\
\hline & Higher potential for conflict $\Rightarrow$ Infrastructure destruction $\Rightarrow$ Slower spread of infections & - \\
\hline \multirow{2}{*}{$\begin{array}{l}\text { Public sector } \\
\text { corruption }\end{array}$} & Reduced government revenue $\Rightarrow$ Lower quality public services & + \\
\hline & Disparities in access to quality healthcare & + \\
\hline Pandemic preparedness & Sector-specific capacity $\Rightarrow$ Faster and better coordinated crisis response & - \\
\hline \multirow{4}{*}{ Federalism } & Local accountability $\Rightarrow$ Improved public services at local level & - \\
\hline & Improved knowledge on local conditions $\Rightarrow$ Better targeted policy-making & - \\
\hline & More difficult coordination between units $\Rightarrow$ Duplication of efforts and diverging interests & + \\
\hline & Multiple tiers of government $\Rightarrow$ More state agents $\Rightarrow$ Greater scope for corruption $\Rightarrow$ Lower quality public services & + \\
\hline Government effectiveness & Increased general state capacity $\Rightarrow$ Better policy implementation & - \\
\hline \multirow{2}{*}{$\begin{array}{l}\text { Past pandemic } \\
\text { exposure }\end{array}$} & Bureaucratic learning $\Rightarrow$ Faster and better coordinated crisis response & - \\
\hline & Past individual experience $\Rightarrow$ Greater acceptance of rules and compliance & - \\
\hline Institutional trust & Greater compliance with government directives & - \\
\hline \multirow{2}{*}{$\begin{array}{l}\text { Interpersonal } \\
\text { trust }\end{array}$} & Fewer barriers to collective action $\Rightarrow$ Greater cooperation $\Rightarrow$ Increased compliance & - \\
\hline & Larger social networks $\Rightarrow$ More frequent social interactions $\Rightarrow$ More infections & + \\
\hline \multirow{4}{*}{ Democracy } & Greater political legitimacy $\Rightarrow$ Greater acceptance of rules and compliance & - \\
\hline & Increased accountability $\Rightarrow$ Better public goods provision & - \\
\hline & Increased political responsiveness $\Rightarrow$ Priority of public health or of economy & $+1-$ \\
\hline & Greater need for negotiation in decision-making $\Rightarrow$ Slower and more diffuse crisis response & + \\
\hline PR electoral system & Greater public goods provision $\Rightarrow$ More equitable access to public services & - \\
\hline \multirow{2}{*}{$\begin{array}{l}\text { Media } \\
\text { independence }\end{array}$} & Increased accountability $\Rightarrow$ Faster and better coordinated crisis response & - \\
\hline & Increased political responsiveness $\Rightarrow$ Priority of public health or of economy & $+1-$ \\
\hline \multirow{4}{*}{ Oil rents } & Decreased accountability $\Rightarrow$ Greater public sector corruption $\Rightarrow$ Lower quality public services & + \\
\hline & Decreased political responsiveness $\Rightarrow$ Worse quality public services & + \\
\hline & Weaker institutions $\Rightarrow$ Greater deficiencies in policy implementation & + \\
\hline & Greater potential for conflict $\Rightarrow$ Lower state capacity and reduced compliance & + \\
\hline \multirow{4}{*}{ Populism } & Sharper cultural divides $\Rightarrow$ Diminished trust and reduced cooperation & + \\
\hline & Reduced accountability and state capacity $\Rightarrow$ Poorer crisis response & + \\
\hline & Reduced accountability and state capacity $\Rightarrow$ Lower quality public services & + \\
\hline & Science skepticism $\Rightarrow$ Distrust of evidence $\Rightarrow$ Poorer crisis response & + \\
\hline
\end{tabular}


Table 11 - continued from previous page

\begin{tabular}{lll}
\hline & Reduced policy moderation capacity $\Rightarrow$ Poorer policy response \\
\hline $\begin{array}{l}\text { Woman } \\
\text { leaders }\end{array}$ & Gendered preference for public goods $\Rightarrow$ Improved health care quality \\
Gendered political priorities $\Rightarrow$ Priority of public health or of economy
\end{tabular}




\section{Distribution of beliefs from priors survey}

We present below a breakdown of results from the experts survey; the instrument can be found at https://www.dropbox.com/s/e0nag4d5g3peds4/covid_correlates_priors_survey.pdf?dl=0.

Figure 6: Current distribution of beliefs

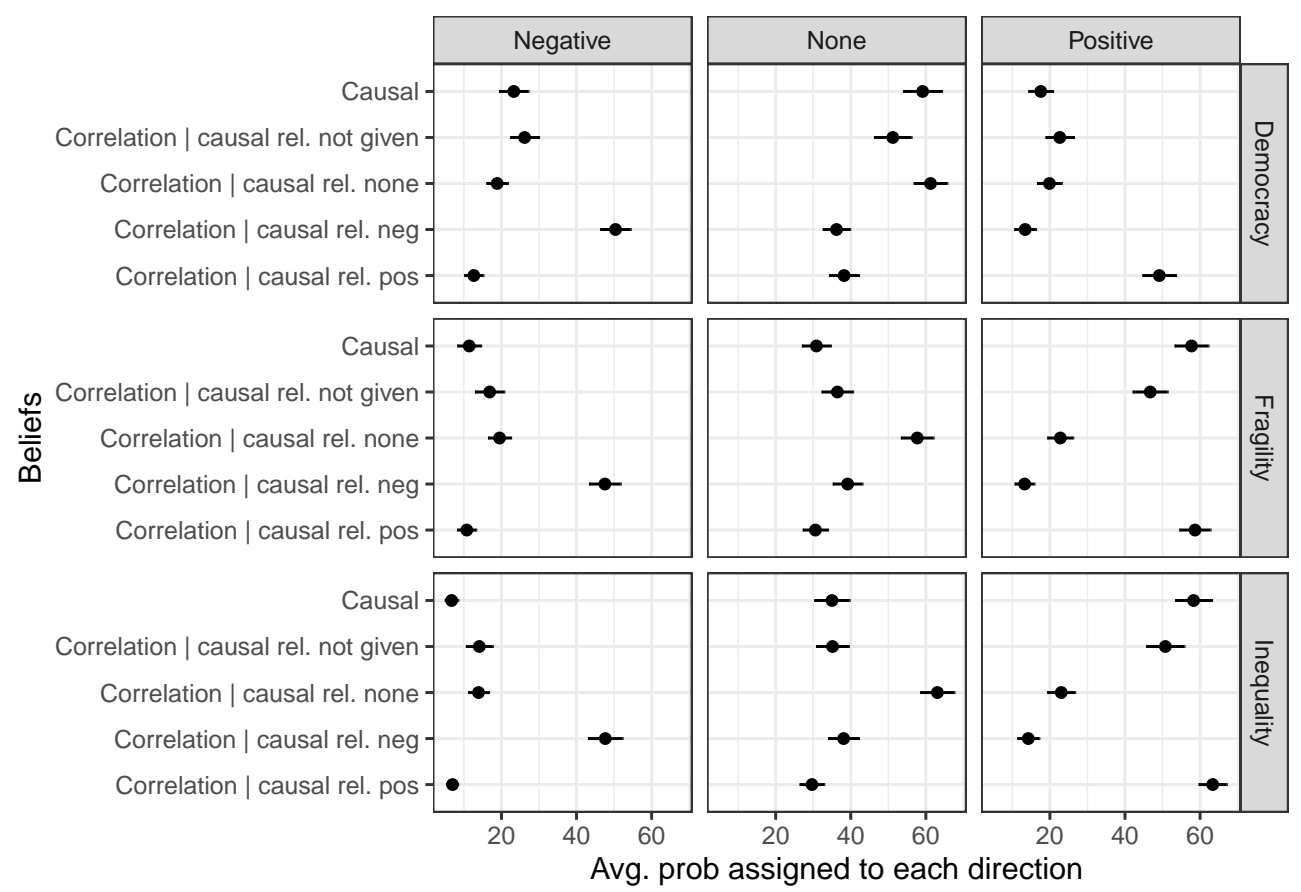

\section{Excess deaths analysis}

A potential concern with official data on Covid mortality is that variation may reflect, in part, cross-national differences in reporting standards and reporting capacity. To allay concerns, we replicate our analysis using excess mortality figures ("excess deaths") as the outcome.

In Figure 7 on page 17 we present two sets of results. First, we provide the estimates using the reported deaths outcome but for the subset of countries for which excess death data is available. This is a smaller set of countries and is a non random subset of the countries in our main analysis. The second column shows results for the same set of countries using excess deaths as the outcome. ${ }^{1}$ Since the timing of excess death reporting differs by country, these models use data from the most recent date for which excess death data is measured in the Economist data. This contrasts our main results in the paper, where we always compare countries at the same point in time.

The following plot shows results from regression models similar to those reported in the main analysis, but where the outcome is logged Covid-19 excess deaths per one million population. For the plot itself, we use a specific transformation of the outcome, to address the case of negative excess deaths: $\log \left(1-x+\frac{E D}{P O P}\right)$,

\footnotetext{
${ }^{1}$ The excess deaths indicator captures the difference between the total number of people who died for any reason during a particular period, and the historical average for the same place and time of year.
} 
where $E D$ is cumulative excess deaths $P O P$ denotes the population (in millions). $x$ is the minimum value, across all countries, of the ratio between excess deaths and population.

We find that results using the excess death outcome are largely similar to our main results. We again observe negative associations between death rates and government effectiveness, inequality, institutional trust, and interpersonal trust. Indeed the results on governmental effectiveness, interpersonal trust, and inequality are statistically stronger using the excess deaths data for this subset of countries (see Figure 7).

Figure 7: Correlates of Covid-19 excess deaths

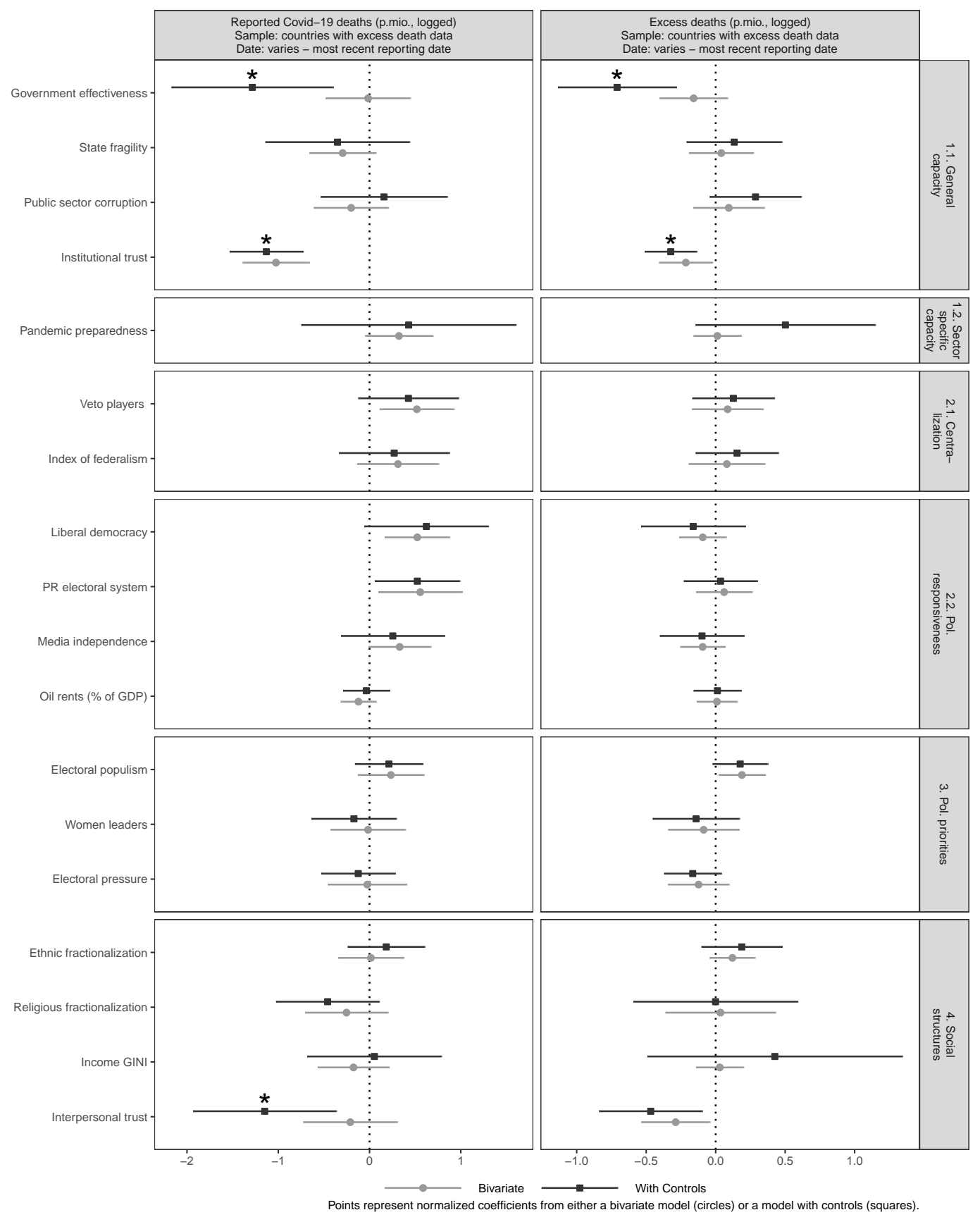




\section{Expert survey}

We recruited participants for an online experts survey through an open call on Twitter encouraging social scientists to take the survey. We also solicited responses by sending invitations for survey participation through multiple political science and public health listservs, and to individual scholars within our networks engaged in public health research. The survey was designed using the Qualtrics platform and was open for 33 days, from July until August, 2020. By the end of this period, we had received responses from a total of 388 individuals. For the analyses presented in this paper, we use data from only 138 of these individuals. We arrive at this response rate of 36 percent by excluding those who spent less than 4 minutes on the survey and those who left the survey without completing all required questions. No incentives were offered to survey respondents and (for the sample of 138 respondents we use for this paper's analysis), survey completion took 20 minutes on average.

Approximately 72 percent of survey respondents had been trained in political science and 51 percent identified themselves as faculty. The tables below offer a more detailed breakdown:

\begin{tabular}{lc}
\hline Discipline & Frequency \\
\hline Economics & 15 \\
Political Science & 100 \\
Sociology & 6 \\
Other or combination & 17 \\
\hline
\end{tabular}

\begin{tabular}{lc}
\hline Rank & Frequency \\
\hline Faculty & 70 \\
Research staff & 28 \\
Student & 28 \\
Policymaker / practitioner & 6 \\
Other & 6 \\
\hline
\end{tabular}

\section{Performance of control variables}

Figure 8 shows how these controls perform in predicting out-of-sample per-capita mortality. Akin to a leave-one-out approach, we predict mortality for a given country based on experiences in all other countries. Each point in the figure shows the actual and predicted $(\log )$ mortality for a given country. The control variables account for only $42 \%$ of the cross-national variation in per-capita mortality. Currently, we observe that the controls perform relatively well. We see the highest predicted and actual concentration in high-income countries, which is notable as regional dummies are not included in the analysis. In middle income countries, Latin American cases do especially poorly and Asian countries relatively well, compared to predictions. African cases are scattered widely on both sides of the prediction line, with, for instance, Sierra Leone with more deaths than expected and Uganda fewer.

\section{Machine learning}

In this supplementary analysis we use a simple machine learning approach to identify, using historical data, plausible future predictors of Covid-19 mortality. We use a Lasso procedure that automatically selects a relatively small subset of the full set of predictors. In essence, the Lasso procedure selects a number of influential predictors and then constrains the sum of the coefficients on those predictors to avoid overfitting.

We note that the procedure is stochastic and each implementation, even with the same data, selects different collections of variables. The Lasso procedure has access to the greatest amount of data, including multiple 
Figure 8: Out of sample predictions from controls

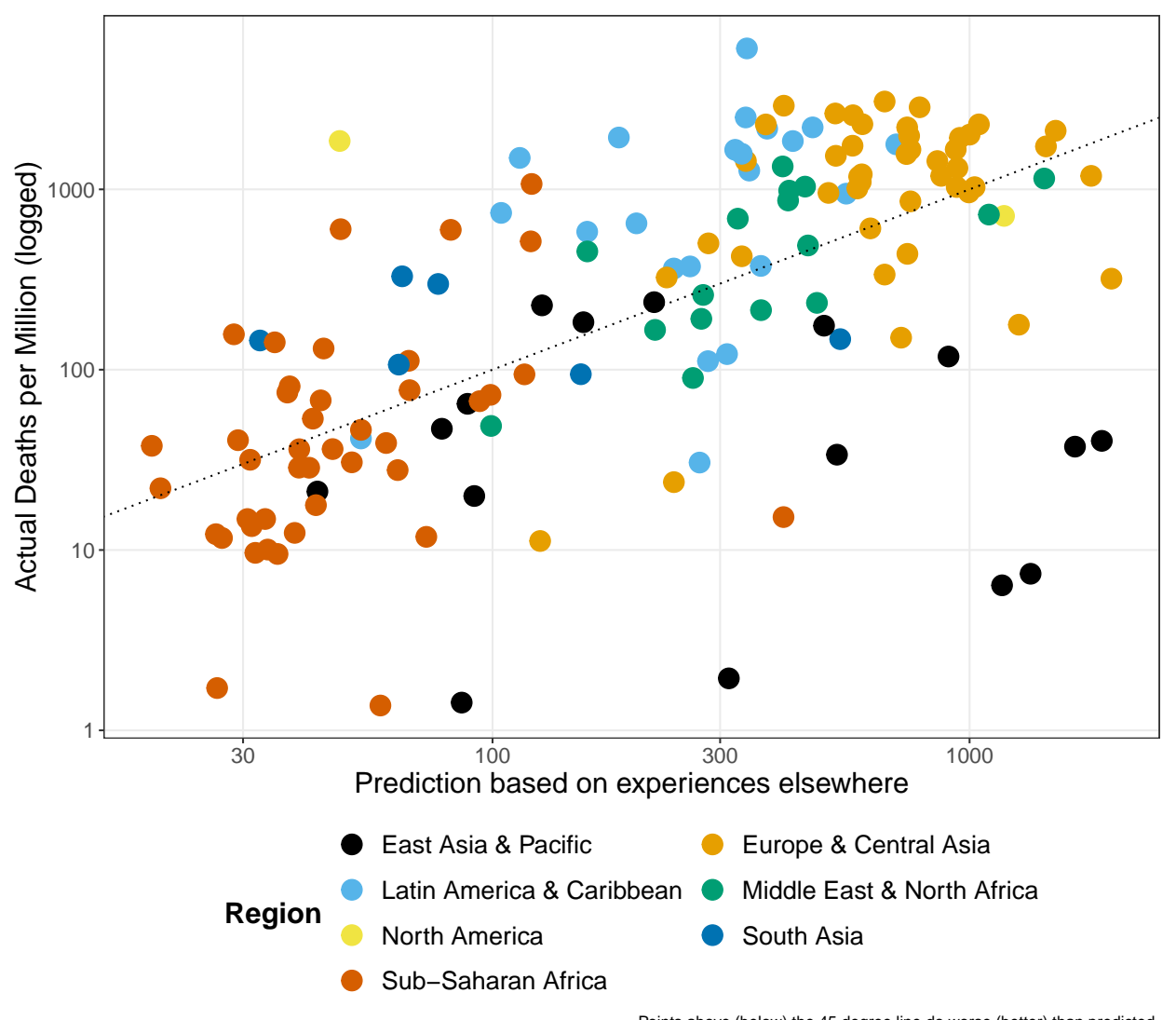

versions of measures used in the classical analysis. It is restricted however to data with relatively low levels of missingness and so does not include the trust measures that rose to prominence in the classical approach.

We present two findings from this analysis.

The first finding relates to the set of political and social variables that do get selected. Table 12 summarizes the most (and least) frequently selected variables (selected using data from end of August 2020, the date of the close of our expert survey). We see that a small set of variables are selected with great frequency, these include whether a political system includes many veto points and whether a proportionate representation system is used. Other variables are never selected, including whether a system is broadly characterized as a liberal democracy.

The second finding relates to the predictive success of these models. Figure 9 on page 20 shows the performance of variables selected in August 2020 in predicting future disease burdens. We see in this period that the selected variables (selected at the most leftward point on the figure) maintain explanatory power and indeed perform better over time (this is not true for variables selected much earlier in the pandemic). In all the Lasso approach appears here to be successful at accounting for variation though there is not strong evidence that-for predictive purposes - attention needs to be paid to political variables in particular. 
Figure 9: Performance of predictions from Lasso models using August 2020 data.
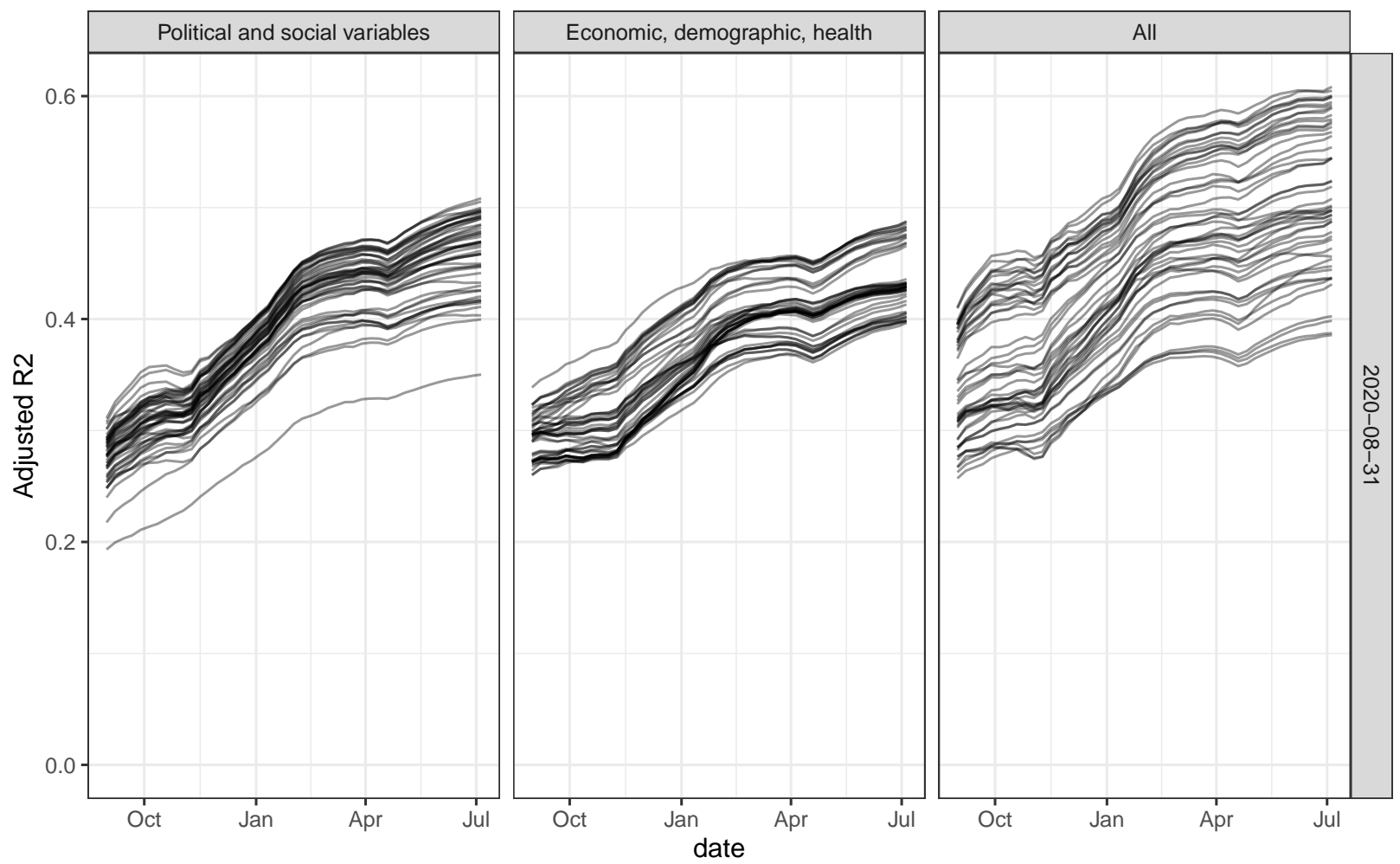

\begin{tabular}{lr}
\hline labels & appearance \\
\hline Print/broadcast media criticalness (VDem) & 0.90 \\
Religious fractionalization & 0.84 \\
State fragility & 0.62 \\
Veto players & 0.60 \\
Left-Right Government & 0.52 \\
Reynal-Querol ethnic polarization & 0.45 \\
Epidemic response capacity & 0.05 \\
Transparent laws with predictable enforcement & 0.04 \\
Share foreign born & 0.04 \\
ELF index & 0.01 \\
Liberal democracy & 0.00 \\
Pandemic preparedness & 0.00 \\
\hline
\end{tabular}

Table 12: Political variables most and least likely to appear in Lasso model. 